\title{
Power Extraction Control of Variable Speed Wind Turbine Systems Based on Direct Drive Synchronous Generator in All Operating Regimes
}

\author{
Youssef Errami $\mathbb{D}^{1},{ }^{1}$ Abdellatif Obbadi, ${ }^{1}$ Smail Sahnoun, ${ }^{1}$ \\ Mohammed Ouassaid, ${ }^{2}$ and Mohamed Maaroufi ${ }^{2}$ \\ ${ }^{1}$ Laboratory of Electronics, Instrumentation and Energy, Team of Exploitation and Processing of Renewable Energy, \\ Department of Physics, Faculty of Science, Chouaib Doukkali University, El Jadida, Morocco \\ ${ }^{2}$ Department of Electrical Engineering, Mohammadia School of Engineers, University Mohammed V, Rabat, Morocco \\ Correspondence should be addressed to Youssef Errami; errami.emi@gmail.com
}

Received 10 January 2018; Accepted 18 March 2018; Published 20 May 2018

Academic Editor: Andrea Bonfiglio

Copyright (C) 2018 Youssef Errami et al. This is an open access article distributed under the Creative Commons Attribution License, which permits unrestricted use, distribution, and reproduction in any medium, provided the original work is properly cited.

\begin{abstract}
Due to the increased penetration of wind energy into the electrical power systems in recent years, the turbine controls are actively occupied in the research. This paper presents a nonlinear backstepping strategy to control the generators and the grid sides of a Wind Farm System (WFS) based Direct Drive Synchronous Generator (DDSG). The control objectives such as Tracking the Maximum Power (TMP) from the WFS, pitch control, regulation of dc-link voltage, and reactive and active power generation at varying wind velocity are included. To validate the proposed control strategy, simulation results for 6-MW-DDSG based Wind Farm System are carried out by MATLAB-Simulink. Performance comparison and evaluation with Vector Oriented Control (VOC) are provided under a wide range of functioning conditions, three-phase voltage dips, and the probable occurrence of uncertainties. The proposed control strategy offers remarkable characteristics such as excellent dynamic and steady state performance under varying wind speed and robustness to parametric variations in the WFS and under severe faults of grid voltage.
\end{abstract}

\section{Introduction}

In the past decades, various renewable energy sources have received increasing attention as alternatives of fossil fuels $[1$, 2]. Among various modern renewable resources, wind power is considered the backbone of renewable power generation. It is regarded as a clean energy resource and it is easily accessible and cost effective. So, wind power penetration greatly increases in the electric power systems and it is anticipated to keep steady growth in the upcoming years $[3,4]$. On the other hand, in modern wind power systems, three of the most promising types of wind turbine generators are the Doubly Fed Induction Generator (DFIG), the Direct Drive Synchronous Generator (DDSG) with permanent magnet, and the Squirrel Cage Induction Generator (SCIG) [5-12]. But, the main advantage of DDSG is the absence of gearbox coupling the wind turbine to the DDSG and the dc external excitation current. So, during the past few years direct driven
DDSGs become very attractive in wind energy application because of their high power density, flexible magnet topologies, reduced maintenance, high effectiveness, high operating efficiency, excellent operation performance, and increased reliability [13-19]. In the area of wind power generation technology, Variable Speed Wind Power Generation System (VS-WPGS) has many advantages over fixed speed ones such as better power quality, higher overall efficiency, lower mechanical stress, and increased energy capture. So, it can be controlled to enable the turbine to operate at its maximum coefficient of power and to ensure the Maximum Power Tracking (MPT) ability [20-22]. To control the VS-WPGS based DDSG, full scale power electronic converter systems are generally used as the interface between the VS-WPGS and the electrical network for satisfying the new standards and grid connection requirements $[23,24]$. Thus, they allow controlling the wind turbine system, decoupling the DDSG from the power grid, and the VS-WPGS does not need to 


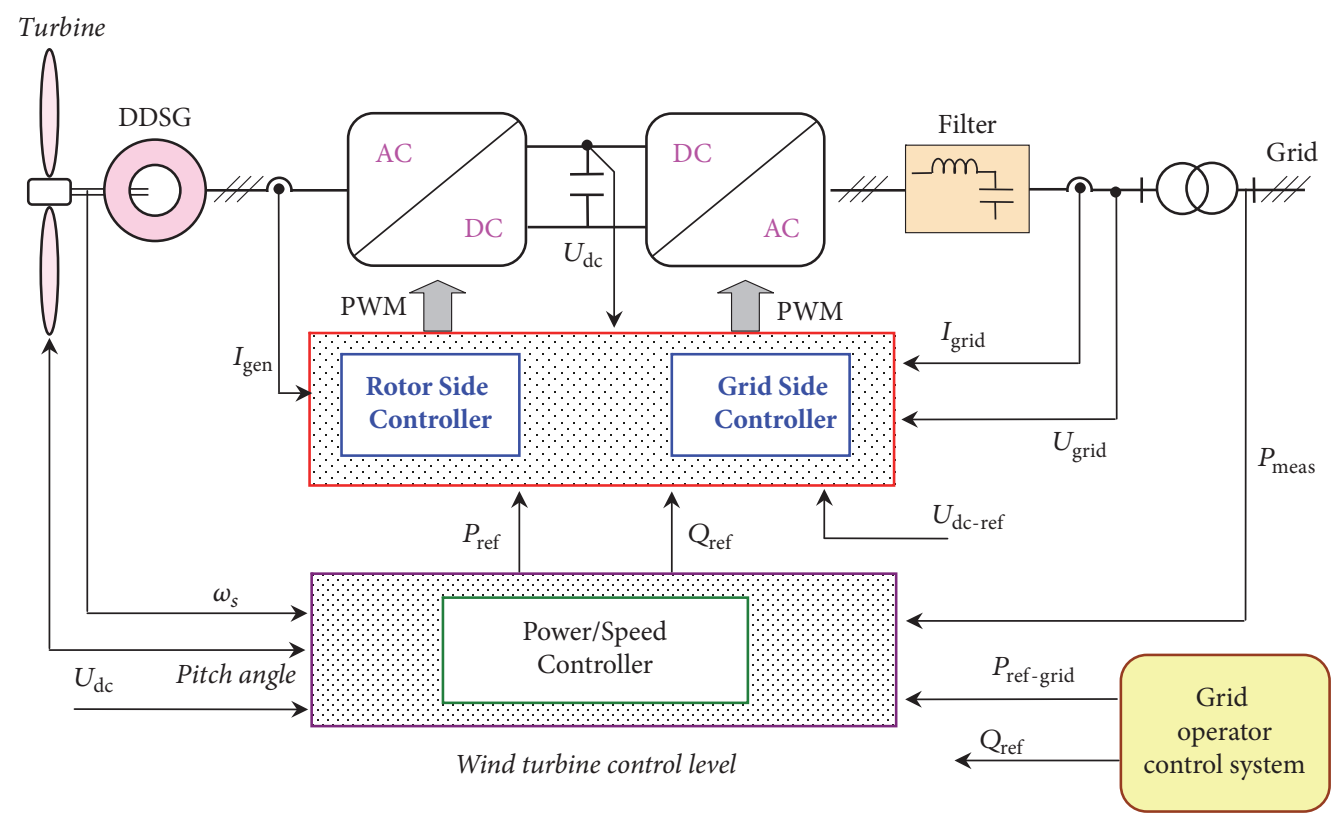

FIGURE 1: Configuration of a VS-WPGS based DDSG.

synchronize its rotational speed with the electrical network frequency [25]. Thus, VS-WPGS is able to attain high efficacy and performance when connected to the electrical network, not only under normal working conditions but also under irregular and faulty network conditions. Figure 1 illustrates the general control structure for VS-WPGS. This consists of a DDSG side and a grid side inverter interconnected through a dc-link system. So, at the DDSG sides, the speed is controlled to ensure the MPT. The grid side converter is employed to regulate the dc-link voltage for a proper transfer of power $[13,19,26,27]$. Also, the inverter system ought to have the ability to regulate reactive and active power that the VS-WPGS exchange with the electrical network and attain unity power factor (UPF) of total system [28]. Various power electronic device configurations were presented in the literature for VS-WPGS based DDSG [29-31]. On the other hand, to increase the annual energy yield of VS-WPGS, MPT control is essential under the rated wind velocity. Then, by changing the rotor velocity of DDSG according to the varying wind velocity, maximum power is extracted from available wind $[21,22,32,33]$.

Also, variable speed wind turbines frequently employ pitch control system, either active stall or pitch to feather, to reduce the aerodynamic power captured $[34,35]$.

According to Fault Ride-Through (FRT) requirements, during faults of grid voltage, the WFS must remain connected to the electric network. As an example, Figure 2 presents a diagram of the FRT requirements in some countries. So, these requirements present a considerable challenge to the wellestablished WFS technologies and their control [36]. Besides, developing effective control approaches WFS will improve the system availability to extract as much power from the wind as possible whereas it is available. On the basic aspect, Vector Oriented Control (VOC) is widely used because of its simple control configuration, ease of design, and economical cost. In $[37,38]$, control strategy has been developed for integrated control of wind turbine based PMSG. The works $[39,40]$ have presented Low Voltage Ride-Through (LVRT) of WECS. But, this technique cannot offer satisfactory control performance if the controlled system is highly nonlinear and uncertain. Moreover, it generally works at particular operating range and it is obligatory to retune the controller if the operating range is modified, whereas the WFS is usually affected by varying the operating condition and outside disturbance.

To overcome the above problems, Direct Control Techniques (DCT) were proposed to substitute the VOC strategy for both rectifier systems and electrical network connection control. Direct power control (DPC) and Direct Torque Control (DTC) of a three-phase converter for fault tolerant DDSG drive were proposed in [29]. The works [19, 41] have proposed TMP algorithm using DTC for DDSG wind turbines. The most important advantages of DCT strategies include low sensitivity to the accuracy of WFS parameter estimation, rapid dynamic response, and easy implementation and they do not necessitate space vector modulation (SVM). But, they can suffer from high torque ripple and variable switching frequency of the power electronic converters and their performances deteriorate at low speed.

On the other hand, modern WFS necessitate efficient and supple technologies that adapt to modifications in load and generation. Also, in order to increase the availability and reliability of WFS, effective strategies are considered crucial means to achieve these goals and to improve the electrical network connected operation capability. Recently, backstepping control approach has received worldwide attention due to its systematic and recursive design methodology for nonlinear control [42]. The stabilization of a virtual control state is the fundamental idea of the backstepping algorithm. This nonlinear control method is principally 


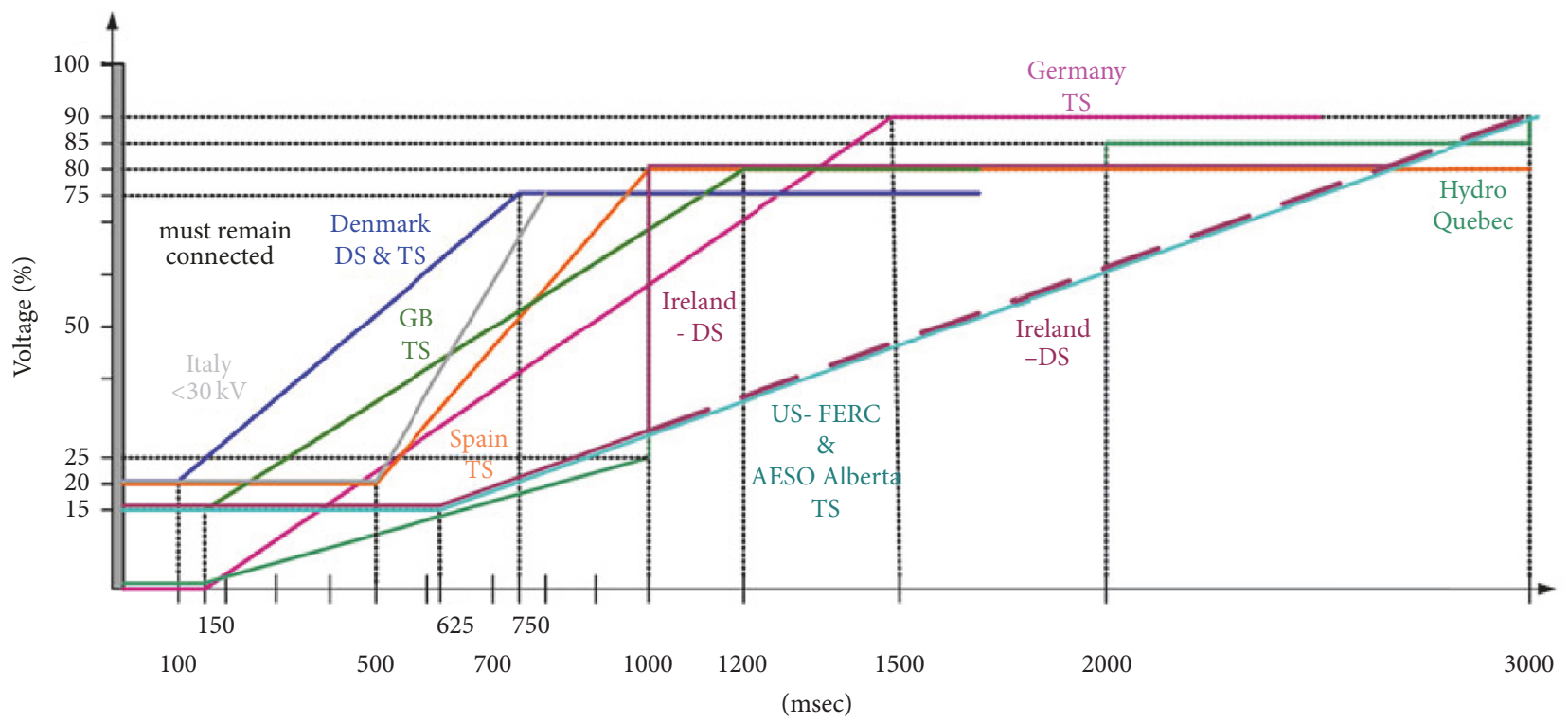

FIGURE 2: National grid codes [36].

interesting due to its capacity to design adaptive controllers for nonlinear systems and to analyze the problem of stability. The advantages of backstepping control are related to the employment of the Lyapunov functions to ensure the robustness and stability of the system, consequently enhancing the performance of system [43]. Also, because of the flexibility to avoid cancellations of suitable nonlinearities and attain the objectives of tracking and stabilization, the backstepping approach has been generally applied in control systems. In the work of [44] backstepping control is developed to deal with the Tracking the Maximum Power (TMP) from the WFS. The work of [45] presents a backstepping control strategy to design a permanent magnet liner synchronous motor servo drive system with uncertainty. Wai et al. [46] proposed the backstepping design for a grid-connected inverter. Ruan et al. [47] proposed an adaptive control strategy using backstepping technique for the Voltage Source Converter (VSC) based High Voltage dc (HVDC) system to develop its dynamic performance. The idea of backstepping approach is to choose recursively some suitable functions of state variables like pseudo-control inputs for lower dimension subsystems of the entire system. The most attractive point of this technique is to employ the virtual control variable to create the original high order system simple. It decomposes a difficult control problem into simpler ones and it chooses recursively suitable functions of state variables which are the virtual control variables. Each backstepping step results in a novel virtual control to deal with a decomposed subsystem problem. So, this virtual control becomes a reference to the next algorithm step for another subsystem. Also, it produces a related error variable that can be stabilized by carefully choosing proper control inputs which can be determined using Lyapunov stability analysis [43]. When the procedure is finished, a true control input for the original control objectives can be generated by summing up the Lyapunov functions associated with each individual design step [48].
This study presents a backstepping control design for the WFS using PMSG, connected to the electrical network. So, a backstepping scheme is developed in the sense of Lyapunov stability theorem to ensure the control objectives of Tracking the Maximum Power (TMP) from the WFS, pitch control, regulation of dc-link voltage, and reactive and active power generation at varying wind velocity. In the first place, mathematical model of WFS is described. In the meanwhile, design of the backstepping technique is provided. Then, simulation studies using MATLAB/Simulink are carried out in Section 3. Finally, some conclusions are summarized in Section 4.

\section{Description of the Proposed WFS}

This section describes the proposed wind energy conversion system using DDSG and presents its modelling and control strategies.

2.1. System Description. The schematic diagram of the gridconnected DDSG-WTS is shown in Figure 3. It is composed of three wind turbines directly linked to DDSGs connected to the grid throughout a converter, which consists of a grid side inverter (GSI) and a generator-side rectifier (MSR). The MSR control the DDSGs to extract the maximum power from the wind [49]. The GSI sustains a constant dc-link voltage and controls the active and reactive power that the WTS exchanges with the electrical power.

So, the converters allow adapting frequencies and voltages between the DDSG terminals and the grid.

2.2. Wind Turbine Characteristics. According to aerodynamics, the maximum power extracted by the rotor blades is expressed as [50]:

$$
P_{w-\max }=\frac{1}{2} \rho_{w} \pi A_{r w}^{2} C_{w-\max }\left(\lambda_{w-m}, \beta_{w}\right) v_{w}^{3}
$$




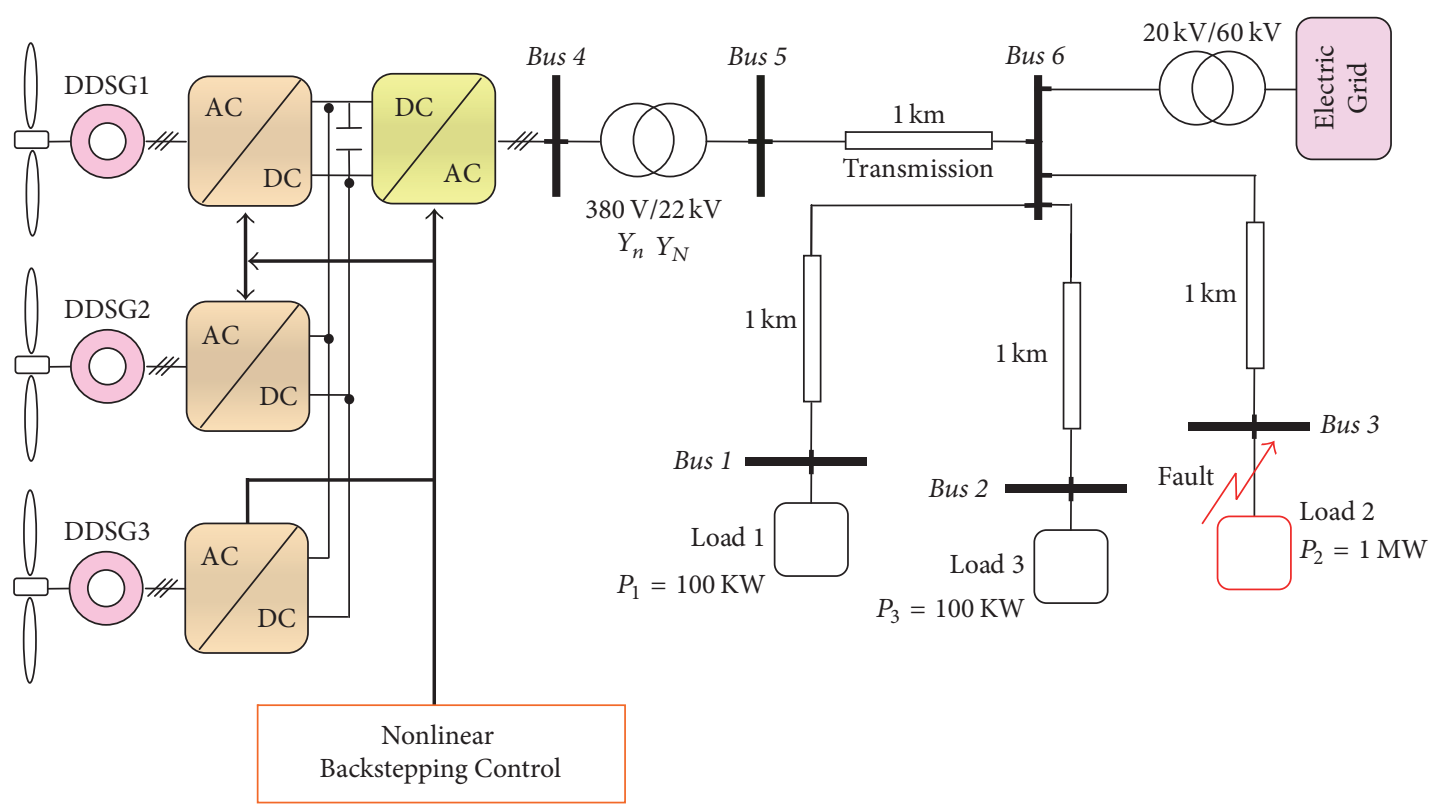

FIgURE 3: Configuration of the VS-WFS.

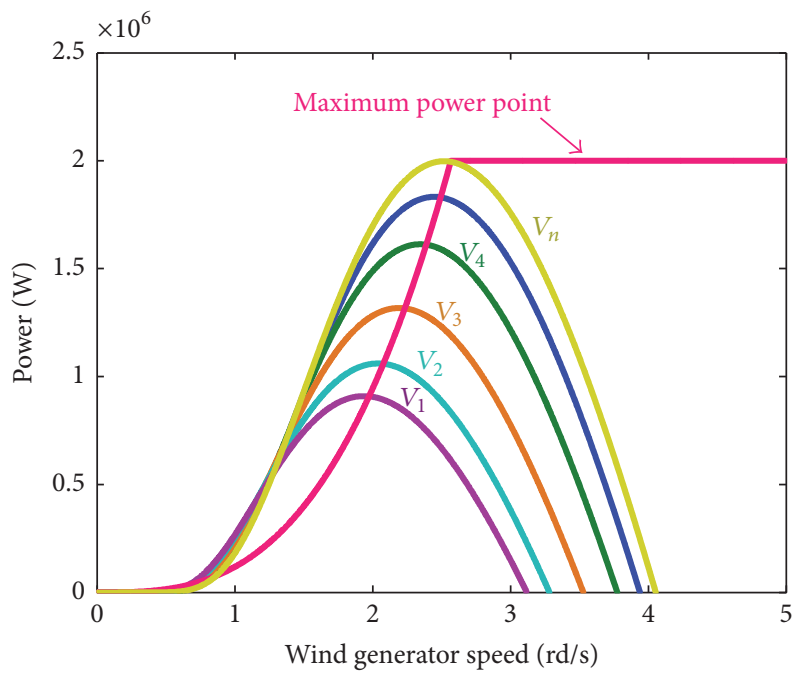

Figure 4: Wind turbine power curves at different values of wind speed.

where $\rho_{w}$ is the air density, $A_{r w}$ is the rotator radius, $v_{w}$ is the speed of wind, $\lambda_{w-m}$ is the optimal tip speed ratio (TSR), $C_{w \text {-max }}\left(\lambda_{m}, \beta_{w}\right)$ is the maximum value of the performance coefficient of the turbine, and $\beta_{w}$ is the blade pitch angle. The tip speed ratio $\lambda_{w}$ is determined by the rotor speed $\omega_{r}$ and the wind speed as

$$
\lambda_{w}=\frac{\omega_{r} A_{r w}}{v_{w}} .
$$

So, an efficient TMP is fundamental for WFS to develop the energy capture effectiveness from wind and the pitch angle $\beta_{w}$ is set as zero during the TMP operation. The optimal TSR strategy is realized by directly regulating the tip speed ratio, which is calculated by real time using wind velocity and generator speed, to follow a preobtained $\lambda_{w-m}$. Therefore, one way to modify the captured wind power is to adjust the DDSG speed, which is depicted in Figure 4 [51]. As seen, different turbine velocities are associated with different captured wind power. Consequently, the generator-side rectifiers in Figure 3 regulate the speeds of DDSGs to attain TMP in combination with the pitch control system. Figure 4 depicts the typical wind turbine power-rotor velocity characteristic curves for different wind velocities, where the optimal power curve illustrates the TMP at different conditions of wind speed. The maximum power extracted $P_{w \text {-max }}$ can be obtained as a function of the shaft velocity:

$$
P_{w-\max }=\frac{\rho_{w} \pi A_{r w}^{5} C_{w-\max }}{2 \lambda_{w-m}^{3}} \omega_{r}^{3}=K_{\max } \omega_{r}^{3},
$$

where $K_{\max }$ is the coefficient of rotational velocity for the maximum extracted power through $C_{w \text {-max }}$ at the wind generator. It should be noted that when the wind velocity is high, the generator velocity and power would exceed the maximum value if the MPPT control is still employed. The pitch control is provided to limit the captured power and the generator speed. So, the pitch angle is set to zero to obtain TMP if the speed is below the maximum speed. But, if the velocity exceeds its rated value, the pitch angle is controlled to limit the captured power to the maximum rated value and the WFS would lead to deviating the TMP searching strategy to prevent overspeeding. The pitch control diagram is shown in Figure 5.

2.3. DDSG Dynamic Modelling. If the rotating reference frame is aligned with the magnetic axis of the rotor, the 


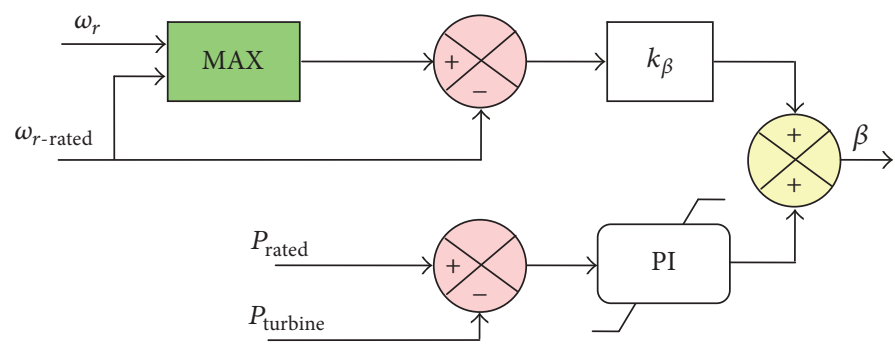

FIgURE 5: Pitch control diagram for generator speed limiting.

electric dynamics equations of a three-phase DDSG can be written in a synchronously rotating $d q$ reference frame as [52]

$$
\left[\begin{array}{c}
v_{\mathrm{sd}} \\
v_{\mathrm{sq}}
\end{array}\right]=\left[\begin{array}{cc}
R_{s}+p \cdot L_{\mathrm{sd}} & -\omega_{e} L_{\mathrm{sq}} \\
\omega_{e} L_{\mathrm{sd}} & R_{s}+p \cdot L_{\mathrm{sd}}
\end{array}\right]\left[\begin{array}{c}
i_{\mathrm{sd}} \\
i_{\mathrm{sq}}
\end{array}\right]+\left[\begin{array}{c}
0 \\
\omega_{e} \psi_{s}
\end{array}\right],
$$

where $v_{\mathrm{sq}}, v_{\mathrm{sd}}$ are stator terminal voltages in the $d q$ frame $(\mathrm{V})$; $i_{\mathrm{sq}}, i_{\mathrm{sd}}$ are direct and quadrature currents components in the stator windings (A); $L_{\mathrm{sq}}, L_{\mathrm{sd}}$ are inductances of the DDSG in the $d q$ frame $(\mathrm{H}) ; R_{s}$ is resistance of the stator windings $(\Omega)$; $\psi_{s}$ is flux linkage generated by the permanent magnets $(\mathrm{Wb})$.

The electrical angular velocity of the rotor, $\omega_{e}$, is defined as

$$
\omega_{e}=p_{n} \omega_{r}
$$

where $p_{n}$ is the number of pole pairs of the generator; $\omega_{r}$ is the mechanical angular velocity $(\mathrm{rad} / \mathrm{sec})$.

If the DDSG is assumed to have equal $q$-axis, $d$-axis in inductances $\left(L_{\mathrm{sq}}=L_{\mathrm{sd}}=L_{\mathrm{gs}}\right)$, the torque developed by the DDSG is

$$
T_{\mathrm{sg}}=\frac{3}{2} p_{n}\left[\psi_{s} i_{\mathrm{sq}}\right]
$$

The generator velocity in the one-mass model of the wind turbine systems is given as follows:

$$
\frac{d \omega_{r}}{d t}=\frac{1}{J_{s}}\left(T_{\mathrm{sg}}-T_{\mathrm{wt}}-F_{s} \omega_{r}\right),
$$

where $J_{s}$ is the moment of inertia $\left(\mathrm{Kg} \cdot \mathrm{m}^{2}\right), F_{s}$ is the viscous friction coefficient $\left(\mathrm{Nm} / \mathrm{rad} \cdot \mathrm{sec}^{-1}\right)$, and $T_{\mathrm{wt}}$ is the mechanical torque developed by the wind turbine (WT) $(\mathrm{Nm})$.

2.4. Backstepping Control Design for the MSR. To attain optimum power effectiveness regardless of wind speed variations, the MSR is used to control the DDSG speeds. Control of the MSR permits the generators to regulate the rotational velocities according to the wind variation. On the other hand, the TMP algorithm adopted in this work is the tip speed ratio control. The backstepping control is employed to perform the TMP control of the wind turbine systems. So, according to (2), the reference of the mechanical DDSG speed can be derived as

$$
\omega_{r-\mathrm{ref}}=\frac{\lambda_{w} v_{w}}{A_{r w}} .
$$

For each MSR, the major control objective is to track the velocity reference as

$$
\alpha_{\omega}=\omega_{r-\text { ref }}-\omega_{r} .
$$

The dynamic of the velocity tracking error is expressed as

$$
\frac{d \alpha_{\omega}}{d t}=\frac{d \omega_{r-\mathrm{ref}}}{d t}-\frac{d \omega_{r}}{d t}
$$

From (6)-(7) and (10), we have

$$
\frac{d \alpha_{\omega}}{d t}=\frac{d \omega_{r \text {-ref }}}{d t}-\frac{1}{J_{s}}\left(\frac{3}{2} p_{n}\left[\psi_{s} i_{\mathrm{sq}}\right]-T_{\mathrm{wt}}-F_{s} \omega_{r}\right) .
$$

So, a first Lyapunov function candidate is defined as [53]

$$
\Gamma_{1}=\frac{1}{2} \alpha_{\omega}^{2}
$$

Differentiating (12) gives us

$$
\begin{aligned}
\frac{d \Gamma_{1}}{d t} & =\alpha_{\omega} \frac{d \alpha_{\omega}}{d t} \\
& =\alpha_{\omega} \frac{d \omega_{r \text {-ref }}}{d t}-\frac{\alpha_{\omega}}{J_{s}}\left(\frac{3}{2} p_{n}\left[\psi_{s} i_{\mathrm{sq}}\right]-T_{\mathrm{wt}}-F_{s} \omega_{r}\right) .
\end{aligned}
$$

Equation (13) can be reorganized as

$$
\begin{aligned}
& \frac{d \Gamma_{1}}{d t}=-\delta_{\omega} \alpha_{\omega}^{2}+\frac{\alpha_{\omega}}{J_{s}}\left(J_{s} \delta_{\omega} \alpha_{\omega}+T_{\mathrm{wt}}-\frac{3}{2} p_{n} \psi_{s} i_{\mathrm{sq}}+F_{s} \omega_{r}\right. \\
& \left.\quad+J_{s} \frac{d \omega_{r_{\text {ref }}}}{d t}\right),
\end{aligned}
$$

where $\delta_{\omega}$ is the positive closed-loop feedback constant. According to (14), the backstepping law can be designed as follows:

$$
\begin{aligned}
& i_{\text {sd-ref }}=0, \\
& i_{\text {sq-ref }}=\frac{2}{3 p_{n} \psi_{s}}\left(J_{s} \delta_{\omega} \alpha_{\omega}+J_{s} \frac{d \omega_{r-\text { ref }}}{d t}+F_{s} \omega_{r}+T_{\mathrm{wt}}\right) .
\end{aligned}
$$

If the speed error can be made to zero by selecting proper control input, (14) can be simplified to [54]

$$
\frac{d \Gamma_{1}}{d t}=-\delta_{\omega} \alpha_{\omega}^{2} \prec 0
$$


Consequently, by Lyapunov stability analysis, the velocity controller is asymptotically stable. To stabilize the currents components $i_{\text {sd }}$ and $i_{\text {sq }}$, define the following current errors:

$$
\begin{aligned}
& \alpha_{\text {sd }}=i_{\text {sd-ref }}-i_{\text {sd }} \\
& \alpha_{\text {sq }}=i_{\text {sq-ref }}-i_{\text {sq }},
\end{aligned}
$$

where $i_{\text {sq-ref }}, i_{\text {sd-ref }}$ are the current references. Taking the derivative of $\alpha_{\text {sd }}$ and $\alpha_{\text {sq }}$ with respect to time and using (4), one can obtain

$$
\begin{aligned}
& \alpha_{\mathrm{sd}} \frac{d \alpha_{\mathrm{sd}}}{d t}=\alpha_{\mathrm{sd}}\left[-\frac{1}{L_{\mathrm{gs}}}\left(v_{\mathrm{sd}}+L_{\mathrm{gs}} \omega_{e} i_{\mathrm{sq}}-R_{s} i_{\mathrm{sd}}\right)\right] \\
& =-\lambda_{\mathrm{sd}} \alpha_{d}^{2}+\frac{\alpha_{\mathrm{sd}}}{L_{\mathrm{gs}}}\left[-v_{\mathrm{sd}}-L_{\mathrm{gs}} \omega_{e} i_{\mathrm{sq}}+R_{s} i_{\mathrm{sd}}\right. \\
& \left.+L_{\mathrm{gs}} \lambda_{\mathrm{sd}} \alpha_{\mathrm{sd}}\right] \\
& \alpha_{\mathrm{sq}} \frac{d \alpha_{\mathrm{sq}}}{d t}=\alpha_{\mathrm{sq}}\left[\frac{d i_{\mathrm{sq}-\mathrm{ref}}}{d t}-\frac{d i_{\mathrm{sq}}}{d t}\right]=-\lambda_{\mathrm{sq}} \alpha_{\mathrm{sq}}^{2} \\
& +\frac{\alpha_{\mathrm{sq}}}{L_{\mathrm{gs}}}\left[L_{\mathrm{gs}} \frac{d i_{\mathrm{sq}-\mathrm{ref}}}{d t}-v_{\mathrm{sd}}+\omega_{e} \psi_{s}+R_{s} i_{\mathrm{sq}}+L_{\mathrm{gs}} \omega_{e} i_{\mathrm{sd}}\right. \\
& \left.+\lambda_{\mathrm{sq}} L_{\mathrm{gs}} \alpha_{\mathrm{sq}}\right]
\end{aligned}
$$

where $\lambda_{\text {sd }}$ and $\lambda_{\text {sq }}$ are the positive closed-loop feedback constants. The second Lyapunov function candidate is defined as

$$
\Gamma_{2}=\Gamma_{1}+\frac{1}{2} \alpha_{\mathrm{sq}}^{2}+\frac{1}{2} \alpha_{\mathrm{sd}}^{2}=\frac{1}{2} \alpha_{\omega}^{2}+\frac{1}{2} \alpha_{\mathrm{sq}}^{2}+\frac{1}{2} \alpha_{\mathrm{sd}}^{2}
$$

Differentiating (20) gives us

$$
\frac{d \Gamma_{2}}{d t}=\alpha_{\omega} \frac{d \alpha_{\omega}}{d t}+\alpha_{\mathrm{sd}} \frac{d \alpha_{\mathrm{sd}}}{d t}+\alpha_{\mathrm{sq}} \frac{d \alpha_{\mathrm{sq}}}{d t} .
$$

From (14) and (18)-(19), (21) can be reorganized as

$$
\begin{aligned}
& \frac{d \Gamma_{2}}{d t}=-\delta_{\omega} \alpha_{\omega}^{2}+\frac{\alpha_{\omega}}{J_{s}}\left(J_{s} \delta_{\omega} \alpha_{\omega}+T_{\mathrm{wt}}-\frac{3}{2} p_{n} \psi_{s} i_{\mathrm{sq}}\right. \\
& \left.+F_{s} \omega_{r}+J_{s} \frac{d \omega_{r_{\mathrm{ref}}}}{d t}\right)-\lambda_{\mathrm{sq}} \alpha_{\mathrm{sq}}^{2}+\frac{\alpha_{\mathrm{sq}}}{L_{\mathrm{gs}}}\left[L_{\mathrm{gs}} \frac{d i_{\mathrm{sq}-\mathrm{ref}}}{d t}\right. \\
& \left.-v_{\mathrm{sd}}+\omega_{e} \psi_{s}+R_{s} i_{\mathrm{sq}}+L_{\mathrm{gs}} \omega_{e} i_{\mathrm{sd}}+\lambda_{\mathrm{sq}} L_{\mathrm{gs}} \alpha_{\mathrm{sq}}\right] \\
& -\lambda_{\mathrm{sd}} \alpha_{\mathrm{sd}}^{2}+\frac{\alpha_{\mathrm{sd}}}{L_{\mathrm{gs}}}\left[-v_{\mathrm{sd}}-L_{\mathrm{gs}} \omega_{e} i_{\mathrm{sq}}+R_{s} i_{\mathrm{sd}}\right. \\
& \left.+L_{\mathrm{gs}} \lambda_{\mathrm{sd}} \alpha_{\mathrm{sd}}\right] .
\end{aligned}
$$

The commands $v_{\text {sq-ref }}$ and $v_{\text {sd-ref }}$ are carried out from (22) as

$$
\begin{aligned}
v_{\mathrm{sq}-\mathrm{ref}}= & \omega_{e} \psi_{s}+R_{s} i_{\mathrm{sq}}+L_{\mathrm{gs}} \omega_{e} i_{\mathrm{sd}}+L_{\mathrm{gs}} \frac{d i_{\mathrm{sq}-\mathrm{ref}}}{d t} \\
& +L_{\mathrm{gs}} \lambda_{\mathrm{sq}} \alpha_{\mathrm{sq}} \\
v_{\mathrm{sd}-\mathrm{ref}}= & L_{\mathrm{gs}} \lambda_{\mathrm{sd}} \alpha_{\mathrm{sd}}-L_{\mathrm{gs}} \omega_{e} i_{\mathrm{sq}}+R_{s} i_{\mathrm{sd}} .
\end{aligned}
$$

Using (16) and (23), (22) can be simplified to

$$
\frac{d \Gamma_{2}}{d t}=-\delta_{\omega} \alpha_{\omega}^{2}-\lambda_{\mathrm{sd}} \alpha_{\mathrm{sd}}^{2}-\lambda_{\mathrm{sq}} \alpha_{\mathrm{sq}}^{2} \leq 0 .
$$

Therefore, by Lyapunov stability analysis, the backstepping regulator is asymptotically stable and the control of the DDSG speeds is attained. The control diagram for individual MSR is depicted in Figure 6.

2.5. Nonlinear dc-link Voltage Regulation. The GSI controls the dc-link voltage and transfers the power from turbineDDSG to the grid. Also, it contributes to the reactive and active power control of the overall DDSG system [55]. If the reference frame is rotating synchronously with the electrical grid voltage vector, the dynamic model voltage equations of the electrical network connection in grid voltage oriented reference frame $(d, q)$ are represented as follows:

$$
\begin{aligned}
& \frac{d i_{d \text {-grid }}}{d t}=\frac{1}{L_{g f}}\left(e_{g d}-R_{g f} i_{d \text {-grid }}+\omega_{g} L_{g f} i_{q \text {-grid }}-U_{s}\right) \\
& \frac{d i_{q \text {-grid }}}{d t}=\frac{1}{L_{g f}}\left(e_{g q}-R_{g f} i_{q \text {-grid }}-\omega_{g} L_{g f} i_{d \text {-grid }}\right),
\end{aligned}
$$

where $e_{g d}, e_{g q}$ are the grid side inverter voltage $(d-q)$ components $(\mathrm{V}) ; U_{s}$ is the amplitude of the grid voltage $(\mathrm{V})$; $R_{g f}(\Omega)$ and $L_{g f}(\mathrm{H})$ are the resistance and inductance of the filter; $\omega_{g}$ is the angular frequency of grid; and $i_{d \text {-grid }}$ and $i_{q \text {-grid }}$ are the $d$-axis current and $q$-axis current (A) of the electrical grid, respectively. The active $P_{g}$ and reactive power $Q_{g}$ can be calculated as follows [56]:

$$
\begin{aligned}
P_{g} & =\frac{3}{2} U_{s} i_{d \text {-grid }} \\
Q_{g} & =\frac{3}{2} U_{s} i_{q \text {-grid }} .
\end{aligned}
$$

Equations (26) illustrate that the active and reactive powers are regulated to achieve the required voltage by changing the respective current of the $d$-q-axis. The dc-link voltage equation can be formulated as in the following equation:

$$
C \frac{d V_{\mathrm{dc}}}{d t}=i_{g}-i_{\mathrm{grid}}
$$

where $C$ is the capacitance of the dc-link capacitor $(\mathrm{F}) ; V_{\mathrm{dc}}$ is dc-link voltage $(\mathrm{V}) ; i_{\text {grid }}$ is the current between the dc-link and the grid; and $i_{g}$ is the current between the dc-link and the DDSG stators (A). So, the active power along the side of the GSI is

$$
V_{\mathrm{dc}} i_{\text {grid }}=\frac{3}{2} U_{s} i_{d \text {-grid }}
$$

From (27)-(28), the dc-link voltage dynamics can be calculated as

$$
\frac{d \mathrm{~V}_{\mathrm{dc}}}{d t}=i_{g}-\frac{1}{C} \frac{3}{2} \frac{U_{s}}{V_{\mathrm{dc}}} i_{d \text {-grid }} .
$$




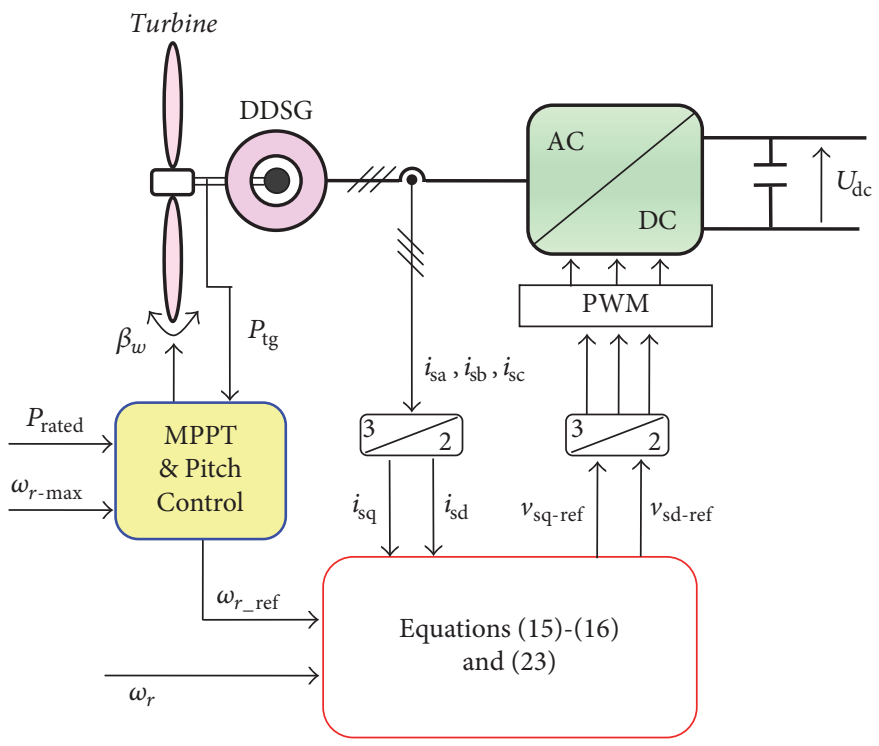

FIGURE 6: Control block diagram of MSR using backstepping approach.

Consequently, to transfer all of the active power generated in turbine-DDSG, the dc-link voltage $V_{\mathrm{dc}}$ must be maintained at a constant value using the current control of $i_{d \text {-grid }}$. Equation (29) can be reorganized as

$$
V_{\mathrm{dc}} C \frac{d V_{\mathrm{dc}}}{d t}=P_{\mathrm{Total}}-\frac{3}{2} U_{s} i_{d \text {-grid }},
$$

where $P_{\text {Total }}$ is the generated power of the DDSGs. Equation (30) can be expressed as

$$
\frac{C}{2} \frac{d V_{\mathrm{dc}}^{2}}{d t}=P_{\text {Total }}-\frac{3}{2} U_{s} i_{d \text {-grid }}
$$

The tracking error of the dc-bus voltage is defined as

$$
\varepsilon_{\mathrm{dc}-\text { link }}=V_{\mathrm{dc}-r}^{2}-V_{\mathrm{dc}}^{2} \text {. }
$$

The dc-link voltage tracking error has the following dynamic:

$$
\frac{d \varepsilon_{\mathrm{dc}-\mathrm{link}}}{d t}=\frac{d V_{\mathrm{dc}-r}^{2}}{d t}-\frac{2}{C}\left(P_{\text {Total }}-\frac{3}{2} U_{s} i_{d-\text { grid- } r}\right),
$$

where $i_{d \text {-grid-r }}$ is the current reference. Consider a third Lyapunov function candidate:

$$
\Phi_{\mathrm{dc}-\mathrm{link}}=\frac{1}{2} \varepsilon_{\mathrm{dc}-\mathrm{link}}^{2} .
$$

From (33), differentiating (34) gives us

$$
\begin{aligned}
& \frac{d \Phi_{\mathrm{dc}-\text { link }}}{d t}=\varepsilon_{\mathrm{dc}-\text { link }} \frac{d \varepsilon_{\mathrm{dc}-\text { link }}}{d t} \\
& =\varepsilon_{\mathrm{dc}-\text { link }}\left[\frac{d V_{\mathrm{dc}-r}^{2}}{d t}-\frac{2}{C}\left(P_{\text {Total }}-\frac{3}{2} U_{s} i_{d \text {-grid-r }}\right)\right] .
\end{aligned}
$$

So, (35) can be reorganized as

$$
\begin{aligned}
& \frac{d \Phi_{\mathrm{dc}-\text { link }}}{d t}=-\lambda_{\text {bus }} \varepsilon_{\mathrm{dc} c \text { link }}^{2}+\varepsilon_{\mathrm{dc}-\text { link }}\left[\frac{d V_{\mathrm{dc}-r}^{2}}{d t}\right. \\
& \left.-\frac{2}{C}\left(P_{\text {Total }}-\frac{3}{2} U_{s} i_{d \text {-grid-r }}\right)+\lambda_{\text {bus }} \varepsilon_{\mathrm{dc}-\text { link }}\right],
\end{aligned}
$$

where $\lambda_{\text {bus }}$ is the positive closed-loop feedback constant. According to (36), the backstepping law can be designed as follows:

$$
i_{d \text {-grid- } r}=\frac{1}{U_{s}}\left[\frac{2}{3} P_{\text {Total }}-\frac{C}{3}\left(\frac{d V_{\mathrm{dc}-r}^{2}}{d t}+\lambda_{\text {bus }} \varepsilon_{\text {dc-link }}\right)\right] .
$$

From (37), (38) can be simplified to

$$
\frac{d \Phi_{\mathrm{dc}-\text { link }}}{d t}=-\lambda_{\mathrm{bus}} \varepsilon_{\mathrm{dc}-\mathrm{link}}^{2} \leq 0 .
$$

Consequently, by Lyapunov stability analysis, dc-link voltage controller is asymptotically stable. To stabilize the currents components $i_{\mathrm{d} \text {-grid }}$ and $i_{\text {-grid }}$, define the following current errors:

$$
\begin{aligned}
& \xi_{d \text {-grid }}=i_{d \text {-grid-r }}-i_{d \text {-grid }} \\
& \xi_{q \text {-grid }}=i_{q \text {-grid-r }}-i_{q \text {-grid }} .
\end{aligned}
$$

The reference $i_{q \text {-grid-r }}$ is calculated from the desired power factor. Based on (37) and (39), (33) can be reorganized as

$$
\frac{d \varepsilon_{\mathrm{dc}-\text { link }}}{d t}=-\lambda_{\mathrm{dc}-\text { link }} \varepsilon_{\mathrm{dc}-\text { link }}+\frac{3}{C} U_{s} \xi_{\mathrm{d} \text {-grid }} .
$$


Besides, from (25) and (39)-(40), one can obtain

$$
\begin{aligned}
& \xi_{d \text {-grid }} \frac{d \xi_{d \text {-grid }}}{d t}=\xi_{d \text {-grid }}\left[\frac{d i_{d \text {-grid-r }}}{d t}-\frac{d i_{d \text {-grid }}}{d t}\right] \\
& =-\lambda_{d \text {-grid }} \xi_{d \text {-grid }}^{2}+\frac{\xi_{d \text {-grid }}}{L_{g f}}\left[L_{g f} \frac{d i_{d \text {-grid-r }}}{d t}-e_{g d}\right. \\
& +U_{s}+R_{g f} i_{d \text {-grid }}-L_{g f} \omega_{g} i_{q \text {-grid }} \\
& \left.+\lambda_{d \text {-grid }} L_{g f} \xi_{d \text {-grid }}\right] \\
& \xi_{q \text {-grid }} \frac{d \xi_{q \text {-grid }}}{d t}=\left[-\frac{d i_{q \text {-grid }}}{d t}\right]=-\lambda_{q \text {-grid }} \xi_{q \text {-grid }}^{2} \\
& +\frac{\xi_{q \text {-grid }}}{L_{g f}}\left[-e_{g q}+R_{g f} i_{q \text {-grid }}+L_{g f} \omega_{g} i_{d \text {-grid }}\right. \\
& \left.+\lambda_{q \text {-grid }} L_{g f} \lambda_{q \text {-grid }}\right],
\end{aligned}
$$

where $\lambda_{d \text {-grid }}$ and $\lambda_{q \text {-grid }}$ are the positive closed-loop feedback constants. Consider the fourth Lyapunov function candidate:

$$
\Phi_{\mathrm{GSI}}=\frac{1}{2} \varepsilon_{\mathrm{dc}-\text { link }}^{2}+\frac{1}{2} \xi_{q \text {-grid }}^{2}+\frac{1}{2} \xi_{d \text {-grid }}^{2}
$$

Differentiating (43) gives us

$$
\begin{aligned}
\frac{d \Phi_{\mathrm{GSI}}}{d t}= & \varepsilon_{\mathrm{dc}-\text { link }} \frac{d \varepsilon_{\mathrm{dc}-\text { link }}}{d t}+\xi_{d \text {-grid }} \frac{d \xi_{\mathrm{d} \text {-grid }}}{d t} \\
& +\xi_{q-\text { grid }} \frac{d \xi_{q-\text { grid }}}{d t} .
\end{aligned}
$$

From (41) and (42), (44) can be reorganized as

$$
\begin{aligned}
& \frac{d \Phi_{\mathrm{GSI}}}{d t}=-\lambda_{\mathrm{dc}-\text { link }} \varepsilon_{\mathrm{dc} \text {-link }}^{2}-\lambda_{d \text {-grid }} \xi_{d \text {-grid }}^{2}-\lambda_{q \text {-grid }} \xi_{q \text {-grid }}^{2} \\
& \quad+\frac{\xi_{d \text {-grid }}}{L_{g f}}\left[\frac{3 L_{g f}}{C} U_{s} \varepsilon_{\mathrm{dc}-\text { link }}+L_{g f} \frac{d i_{d \text {-grid- } r}}{d t}-e_{g d}\right. \\
& +R_{g f} i_{d \text {-grid }}-L_{g f} \omega_{g} i_{q \text {-grid }}+U_{s} \\
& \left.+\lambda_{d \text {-grid }} L_{g f} \xi_{d \text {-grid }}\right]+\frac{\xi_{q \text {-grid }}}{L_{g f}}\left[-e_{g q}+R_{g f} i_{q \text {-grid }}\right. \\
& \left.+L_{g f} \omega_{g} i_{d \text {-grid }}+\lambda_{q \text {-grid }} L_{g f} \xi_{q-\text { grid }}\right] .
\end{aligned}
$$

According to (45), the backstepping law can be designed as follows:

$$
\begin{aligned}
v_{d-\mathrm{GSI}}= & \frac{3 L_{g f}}{C} U_{s} \varepsilon_{\text {dc-link }}+L_{g f} \frac{d i_{d \text {-grid-r }}}{d t}+R_{g f} i_{d \text {-grid }} \\
& -L_{g f} \omega_{g} i_{q \text {-grid }}+U_{s}+L_{g f} \lambda_{d \text {-grid }} \xi_{d \text {-grid }} \\
v_{q-\text { GSI }}= & R_{g f} i_{q \text {-grid }}+L_{g f} \omega_{g} i_{d \text {-grid }}+L_{g f} \lambda_{q \text {-grid }} \xi_{q \text {-grid }} .
\end{aligned}
$$

TABLE 1: Parameters of the DDSG.

\begin{tabular}{lc}
\hline Parameter & Value \\
\hline$P_{r}:$ rated power of DDSG & $2(\mathrm{MW})$ \\
$\omega_{m}:$ rated mechanical speed & $2.57(\mathrm{rd} / \mathrm{s})$ \\
$R:$ stator resistance & $0.008(\Omega)$ \\
$L_{s}:$ stator $d$-axis inductance & $0.0003(\mathrm{H})$ \\
$\psi_{f}:$ permanent magnet flux & $3.86(\mathrm{wb})$ \\
$p_{n}:$ pole pairs & 60 \\
\hline
\end{tabular}

TABle 2: Parameters of the turbine.

\begin{tabular}{lc}
\hline Parameter & Value \\
\hline Blade number & 3 \\
$\rho:$ the air density & $1.08 \mathrm{~kg} / \mathrm{m}^{3}$ \\
$A:$ area swept by blades & $4775.94 \mathrm{~m}^{2}$ \\
$v_{w-n}:$ rated wind speed & $12.4 \mathrm{~m} / \mathrm{s}$ \\
\hline
\end{tabular}

TABLE 3: System parameters.

\begin{tabular}{lc}
\hline Parameter & Value \\
\hline dc-link voltage reference & $2100 \mathrm{~V}$ \\
Grid frequency & $50 \mathrm{~Hz}$ \\
Grid phase voltage & $660 \mathrm{~V}$ \\
Ratio $X_{\text {Grid }} / R_{\text {Grid }}$ & 5 \\
dc-link capacitor & $38000 \mu \mathrm{F}$ \\
\hline
\end{tabular}

Using (37) and (46), (45) can be simplified to

$$
\begin{aligned}
\frac{d \Phi_{\mathrm{GSI}}}{d t} & =-\lambda_{\mathrm{dc}-\text { link }} \varepsilon_{\mathrm{dc} \text {-link }}^{2}-\lambda_{d \text {-grid }} \xi_{d \text {-grid }}^{2}-\lambda_{q \text {-grid }} \xi_{q \text {-grid }}^{2} \\
& \leq 0 .
\end{aligned}
$$

Therefore, by Lyapunov stability analysis, the backstepping regulator is asymptotically stable and the control of the GSI is attained. The control diagram is depicted in Figure 7.

\section{Simulation Result Analysis}

The performance of the proposed nonlinear control strategy is demonstrated in this section. The controller is tested on the WFS control strategy found in Section 2. The schematic of the overall control scheme of the WFS is illustrated in Figure 7. Numerical simulations are carried out using MATLAB/Simulink software to verify WFS performance. System data used are listed in Tables 1, 2, and 3. The performance coefficients of the turbines are evaluated as the following form:

$$
\begin{aligned}
C_{w}\left(\lambda_{w}, \beta_{w}\right) & =\frac{1}{2}\left(\frac{116}{\lambda_{w c}}-0.4 \beta_{w}-5\right) e^{-\left(21 / \lambda_{w c}\right)} \\
\frac{1}{\lambda_{w c}} & =\frac{1}{\lambda_{w}+0.08 \beta_{w}}-\frac{0.035}{\beta_{w}^{3}+1}
\end{aligned}
$$

where $C_{w}$ reaches the maximum value $C_{w-\max }=0.4104$ when $\lambda_{w}$ is $\lambda_{w-m}=8.1$. 


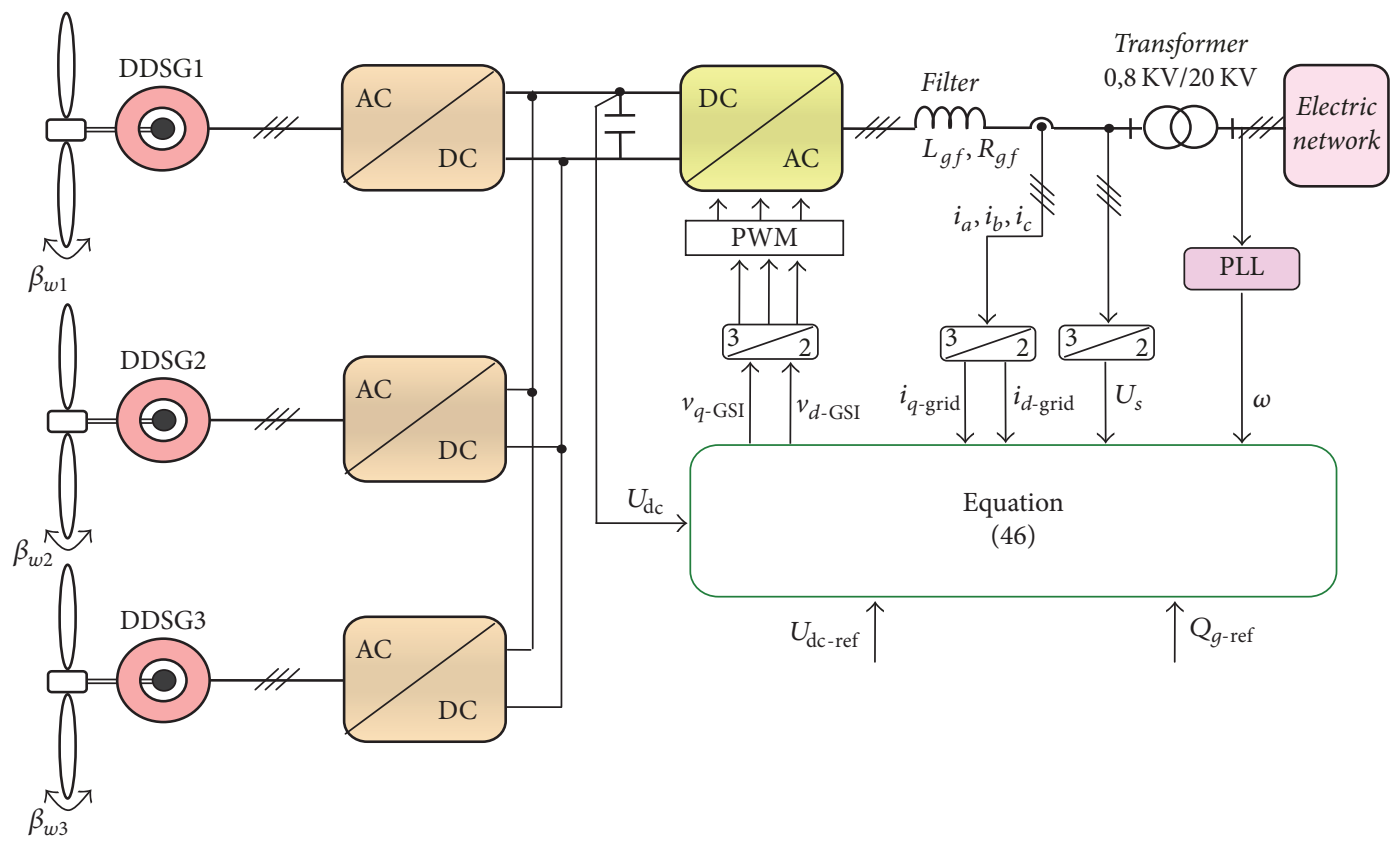

Figure 7: Control block diagram of GSI.

Besides, the simulation will be performed in three steps with different objectives. The first scenario consists in operation under changing wind velocities, the second is robustness of proposed control strategy against electrical and mechanical parameter changes, and the third is an AC voltage sag.

\subsection{Case 1: Performance Evaluation under Normal Operation} of Proposed Control. Figure 8 shows the wind velocities for the different wind turbine systems (a), the individual pitch angle for each wind turbine (b), the performance coefficients of the turbines (c), the speeds of DDSG (d), and the total power extracted by the wind farm (f). It has been noted that the speeds of DDSG are adapted relative to the variation of wind speed and the $C_{w}$ can be preserved at a maximum value which could yield to TMP by working the turbines at the speed references. The pitch angle controls are activated for velocities above the rated wind velocity to control the rated power of the DDSGs. If the wind turbines receive wind velocities which are lower than the rated speed, the pitch angles are set as $0^{\circ}$ to generate the maximum extracted power. The wind turbine systems operated at theirs maximum performance coefficients and the pitch angle were kept at their optimal values. The controller performs the power maximization according to the wind velocity variation. But, pitch controls are activated to restrict the rotational velocities to below the maximum speed and to limit the powers of turbines when the wind velocities are above the rated speed. In this study, the DDSG rated speed is $2.57 \mathrm{rad} / \mathrm{s}$. So, in high wind velocity regions, the DDSG velocities and extracted power would not exceed the maximum. The generated power of the WFS is shown in Figure 8(f). Figure 8(e) shows wind DDSG1 speed follows the optimal speed provided by the TMP operation as the wind velocity varies. The DDSG1 velocity is able to track its optimal values precisely. Figures $8(\mathrm{~g})-8(\mathrm{~h})$ show the currents of DDSG1, where the generator currents are able to track their optimal values precisely. Figure 9 illustrates the dc-link voltage response. The dc-link voltage controller tried to maintain the constant value so that the dclink voltage had an approximately constant value of $2100 \mathrm{~V}$. Figure 10 shows the simulation result of reactive power which is controlled to be zero. Figure 11 illustrates a detailed view of the grid currents and phase voltage during the wind variation where the proposed WFS produces sinusoidal currents at electrical network with unity power factor. The simulation results show that the proposed backstepping controllers have good performance and can guarantee acceptable global regulation and tracking performance to extract and convert power under varying wind speeds.

3.2. Case 2: WFS Response Subject to Parameter Uncertainties. In order to verify the robustness of the proposed control strategy against the variation of parameters, it is supposed that the stator inductance $L_{\mathrm{gs}}$, the stator resistor $R_{s}$, and the total moment of inertia $J_{s}$ of the system values are increased by $50 \%$ under the condition of nominal values. In Figures $12-15$, robustness against WFS parameter variations is tested for the proposed strategy. In the simulation, $L_{\mathrm{gs}}, R_{s}$, and $J_{s}$ are increased to $150 \%$ of their nominal values, and the other simulation parameters are the same as those in first scenario. The simulation results of the backstepping control and the VOC strategy with and without the mentioned parameter variation are shown in Figures 12-15. The results with and without the parameter variations are marked by "A" and "B," respectively. It can be seen that the backstepping strategy has a fast dynamic response, a reduced settling time, and a lower overshoot. The simulation results confirm that the proposed control approach is robust against uncertainties in the WFS compared with conventional VOC. 


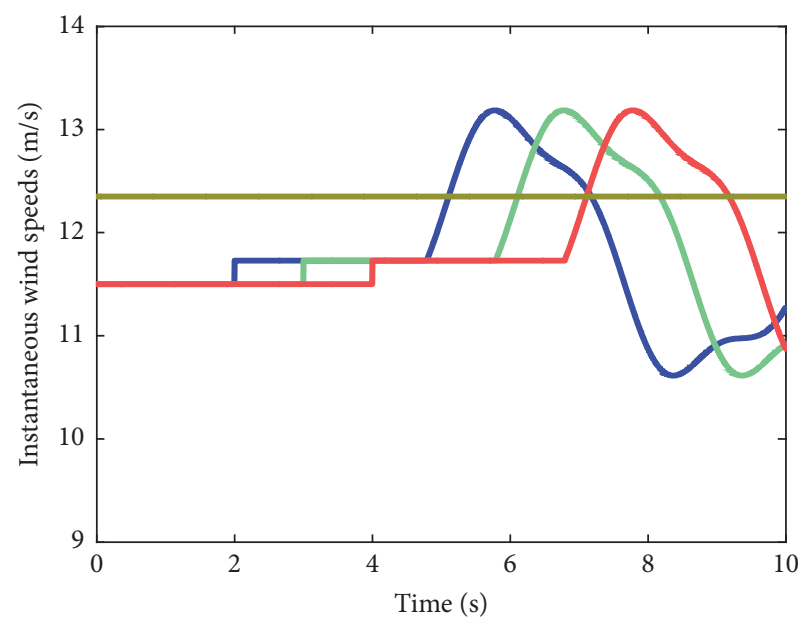

- Wind turbine 1

- Wind turbine 2

— Wind turbine 3

(a) Wind speeds $(\mathrm{m} / \mathrm{s})$

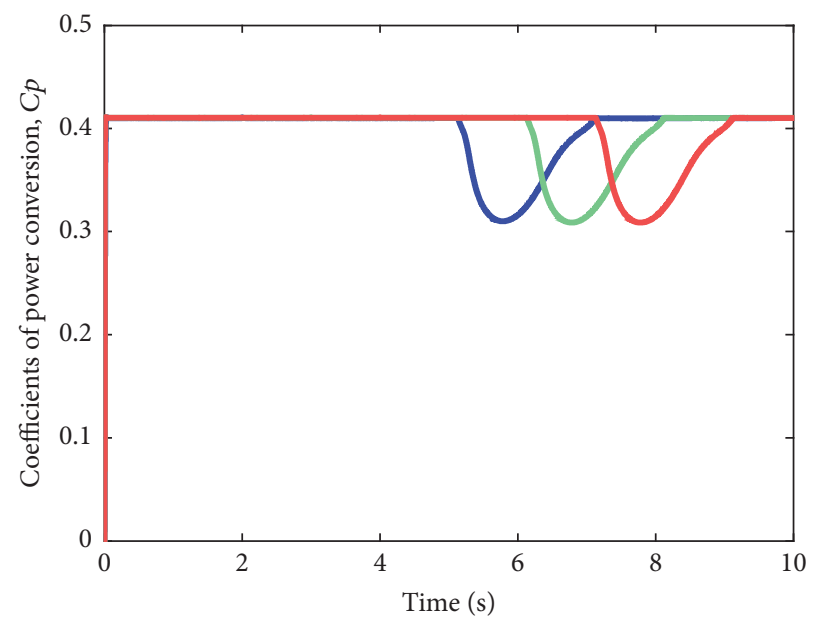

- Wind turbine 1

Wind turbine 2

Wind turbine 3

(c) Coefficient of power, $C_{w}$

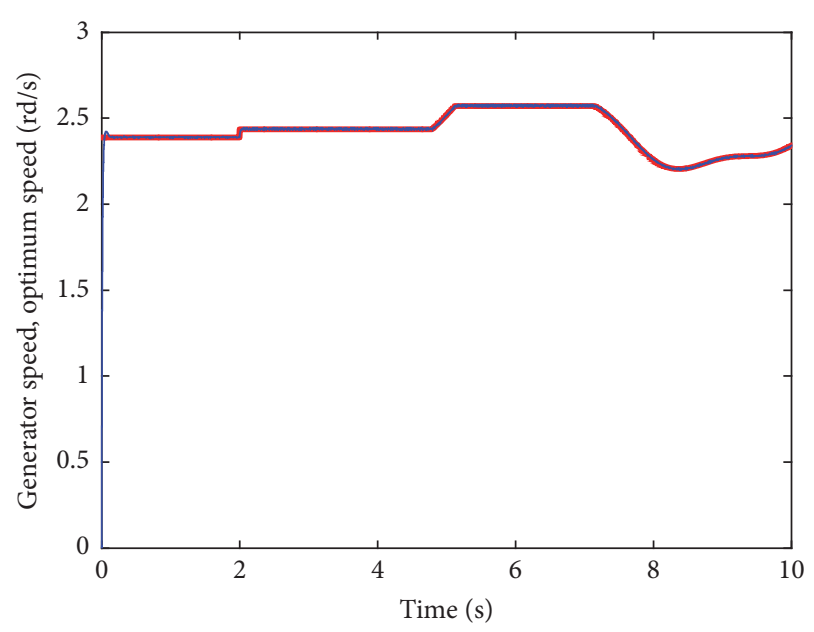

Optimum speed

Generator speed

(e) Speed of DDS1 (rd/s)

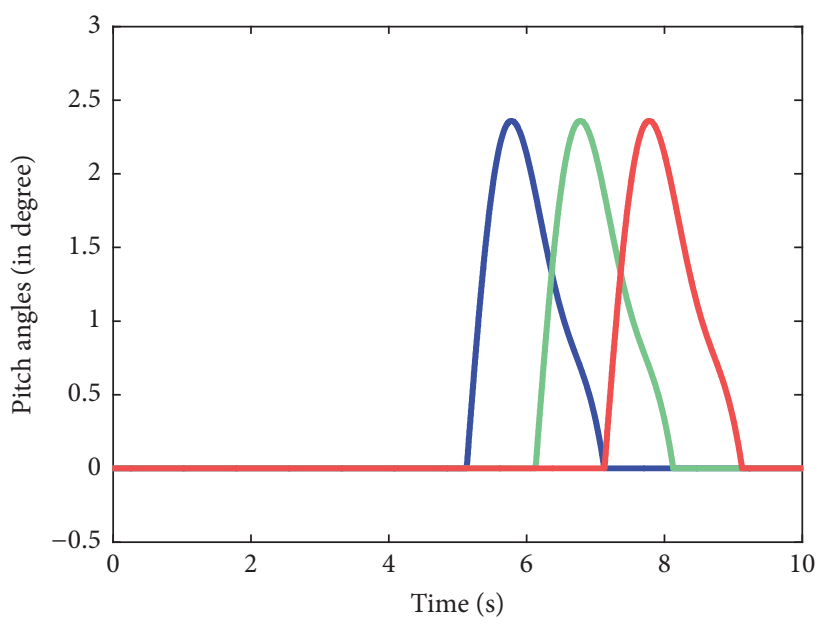

— Turbine 1

Turbine 2

— Turbine 3

(b) Pitch angles $\beta_{w}$ (in degree)

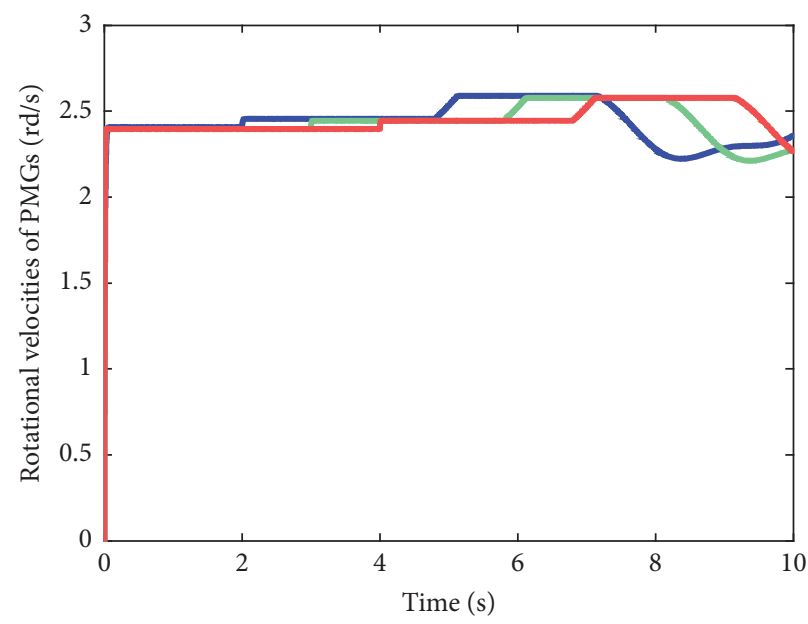

- PMSG 1

PMSG 2

- PMSG 3

(d) Speed of DDSGs (rd/s)

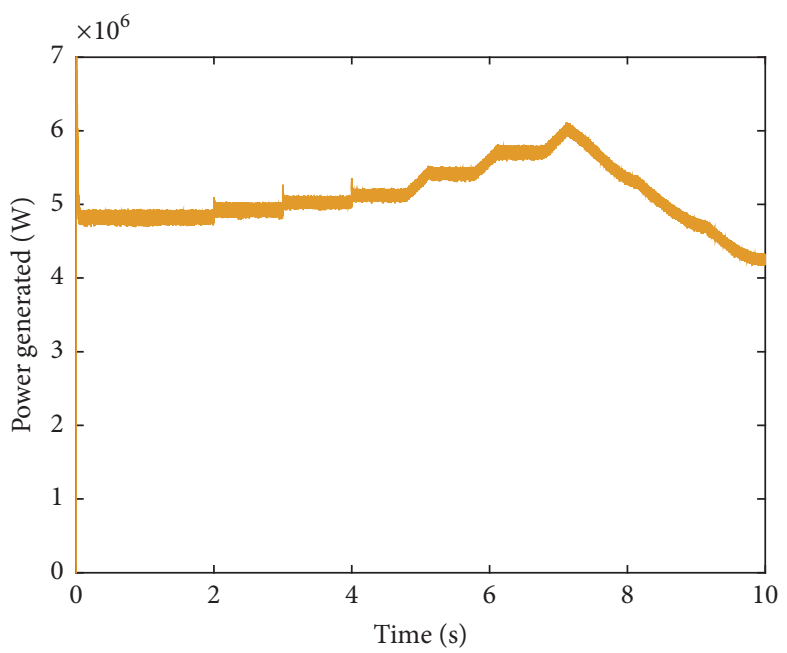



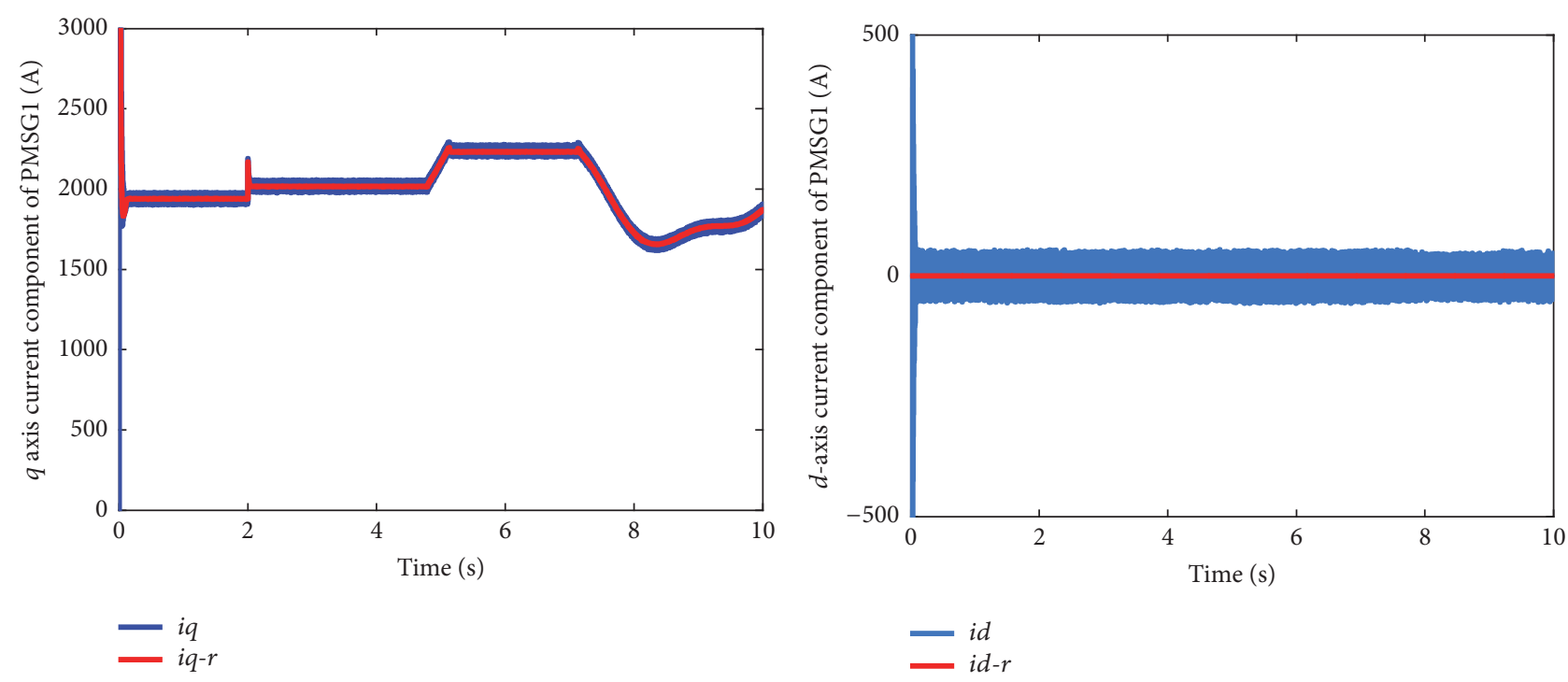

(g) Quadrature current component $i_{\mathrm{sq}}$ of DDSG1 (A)

(h) Direct current component $i_{\text {sd }}$ of DDSG1 (A)

FIGURE 8: Simulation of the WFS in normal operation and using backstepping strategy.

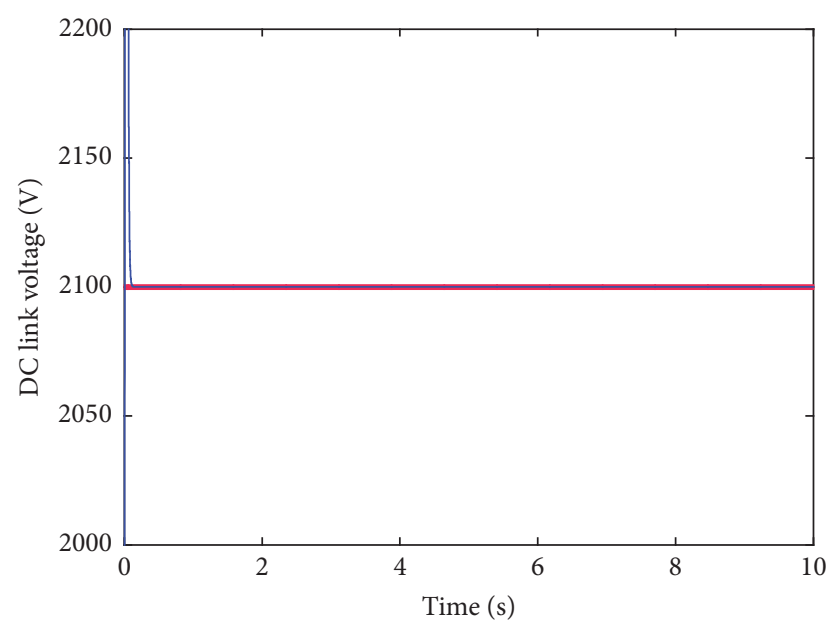

Udc-ref

FIGURE 9: dc-link voltage (V).

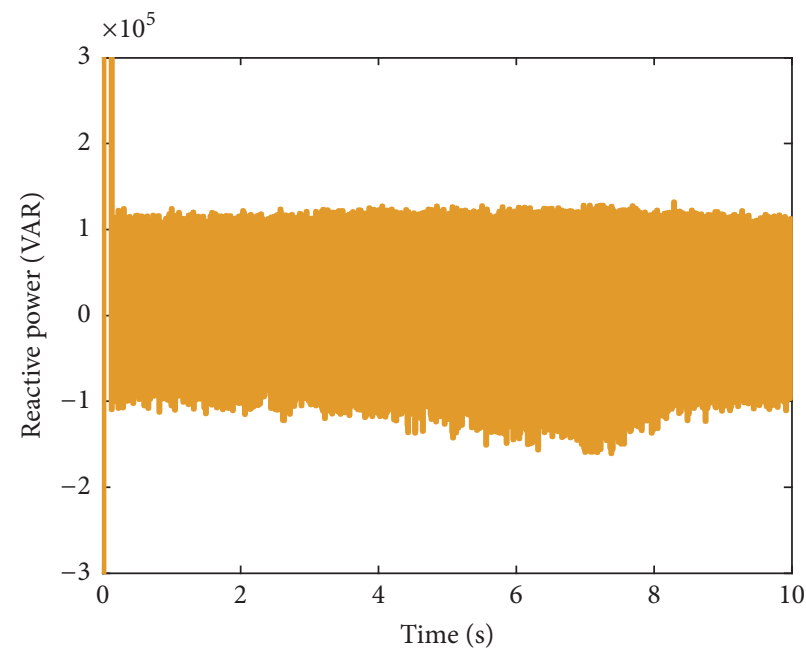

FIGURE 10: Reactive power (VAR). 

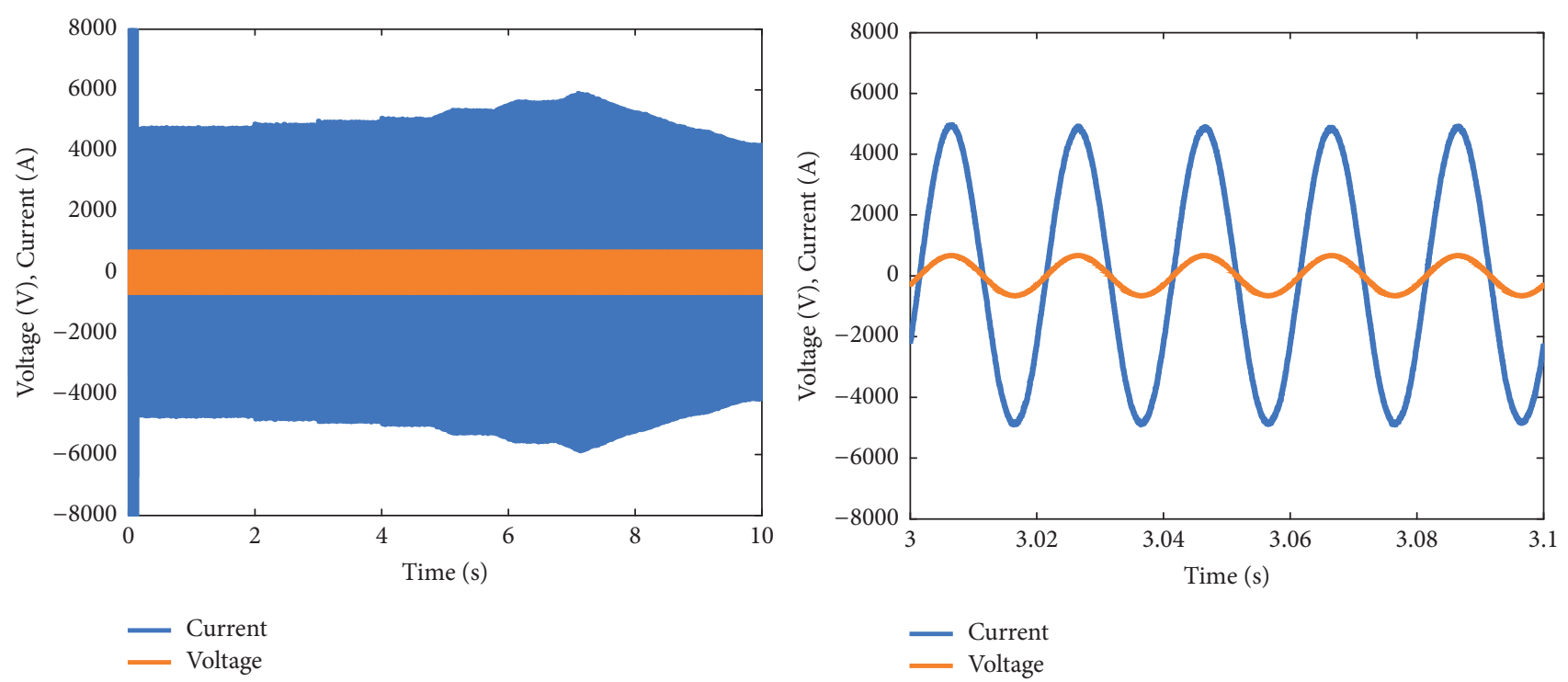

FIGURE 11: Simulation of the three-phase current and voltage of electrical network.

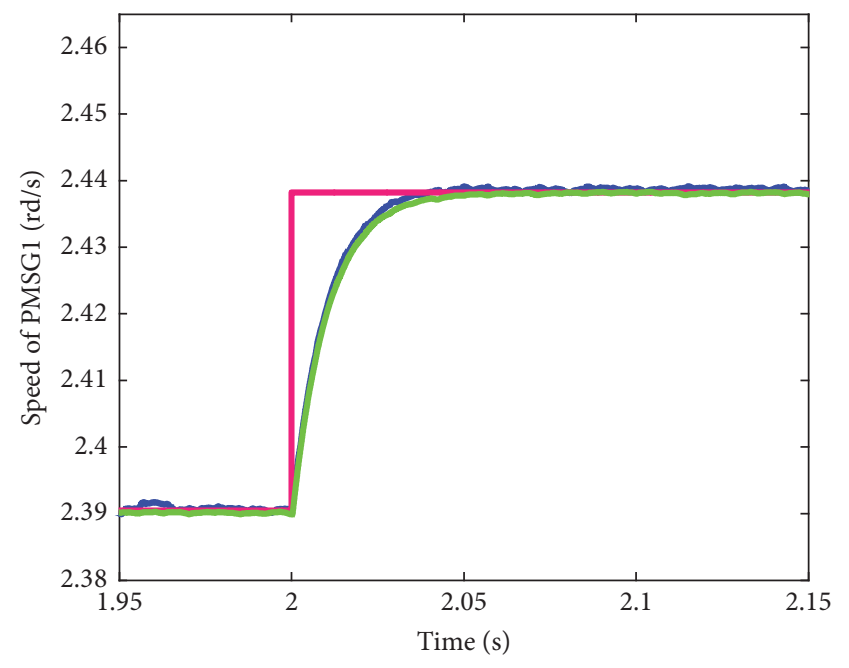

A
- Rated speed
$B$

(a) Backstepping control
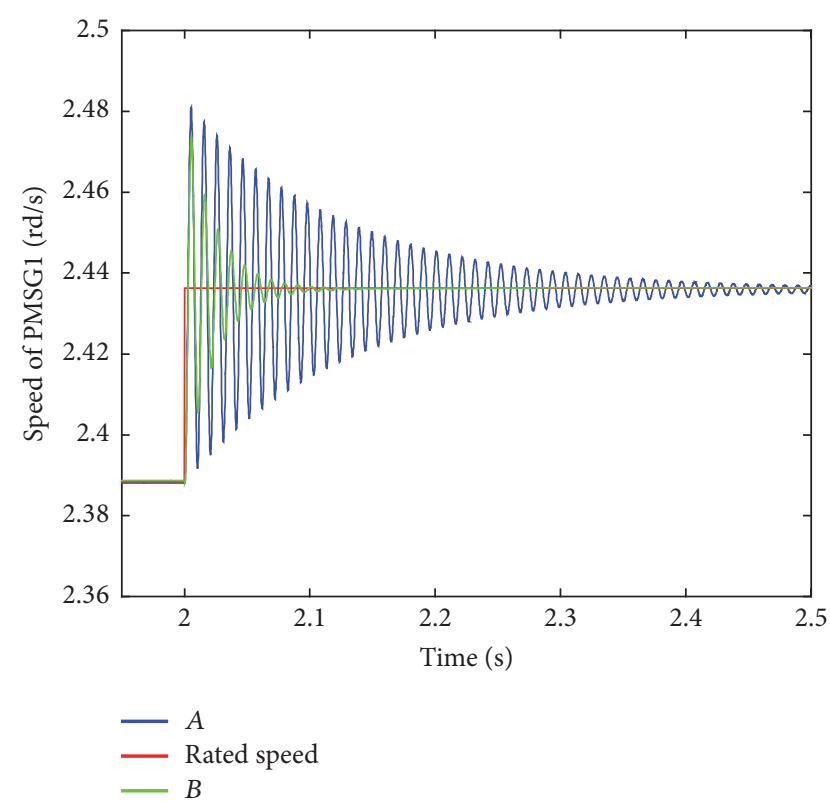

(b) VOC strategy

FIGURE 12: DDSG1 speed (rd/s).

3.3. Case 3: Simulation under Grid Fault Condition. This simulation example deals with the WFS behaviour during a Three-Phase Grid Fault (3PGF) produced at $t=5.5 \mathrm{~s}$ and characterised by a voltage drop of $200 \mathrm{~ms}$ at Bus 3 (Figure 3). Figures 16 and 17 illustrate the voltage of the WFS at Bus 4 in normal and close zoom views, respectively, for backstepping and VOC strategies. It can be observed that, by applying the backstepping controller, the transient stability of the WFS has been enhanced and the oscillations of the three-phase voltage have been damped quickly when the fault is cleared. Besides, Figure 17 shows that the transient duration with the proposed control is faster than that with the VOC and the three-phase voltage oscillation amplitude at VOC is evidently larger than that at backstepping control. The results illustrated that the backstepping control strategy can not only reduce the peak value of three-phase voltage but also shorten the transient response time compared with the VOC strategy. Compared to the results depicted in Figure 18, it can be seen that the peak value of frequency deviations can be eliminated during grid voltage drop with the proposed control strategy. Compared with VOC strategy, the peak value of frequency deviations is reduced from $1.9 \mathrm{~Hz}$ to less than $0.25 \mathrm{~Hz}$ with backstepping strategy. Figure 19 illustrates the dc-link voltage response under proposed control and VOC strategy. The voltage drop 


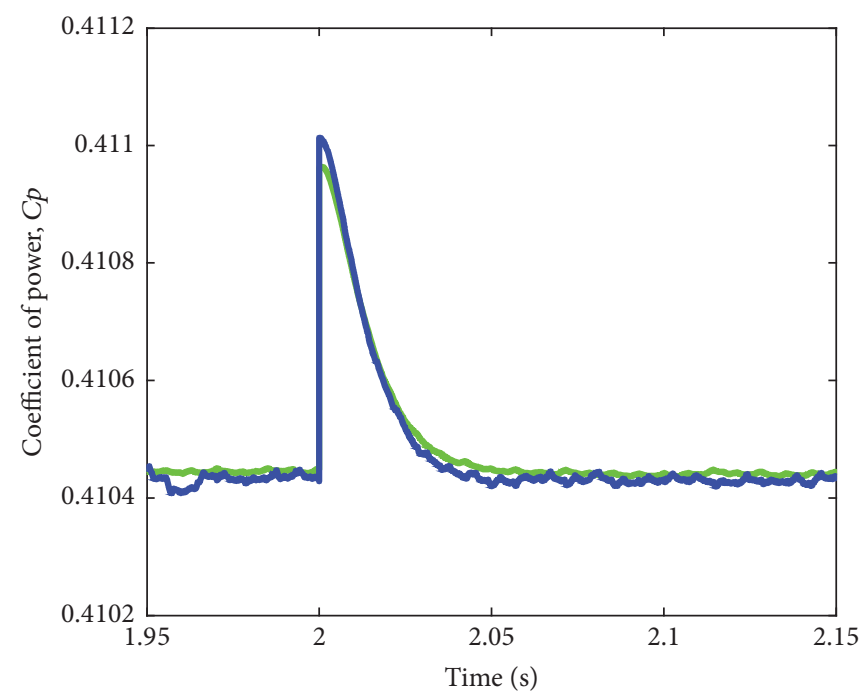

$-B$
-

(a) Backstepping control
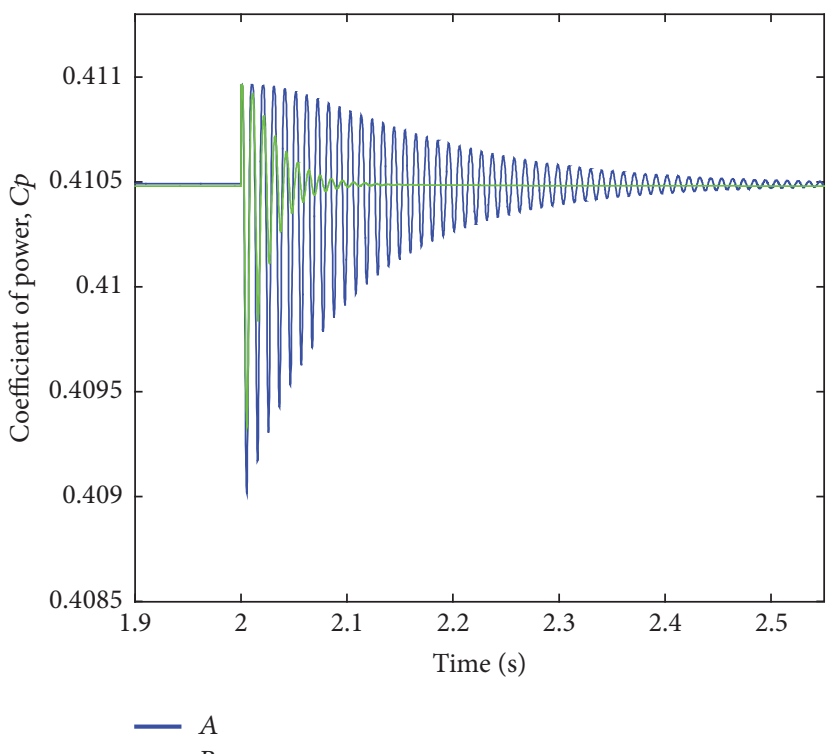

(b) VOC strategy

Figure 13: Coefficient of power.

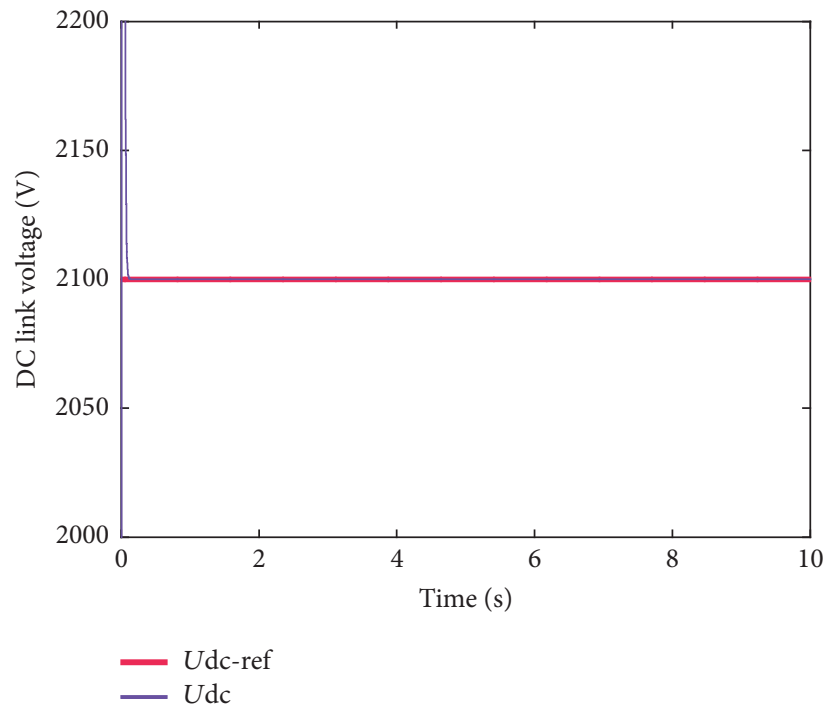

(a) Backstepping control

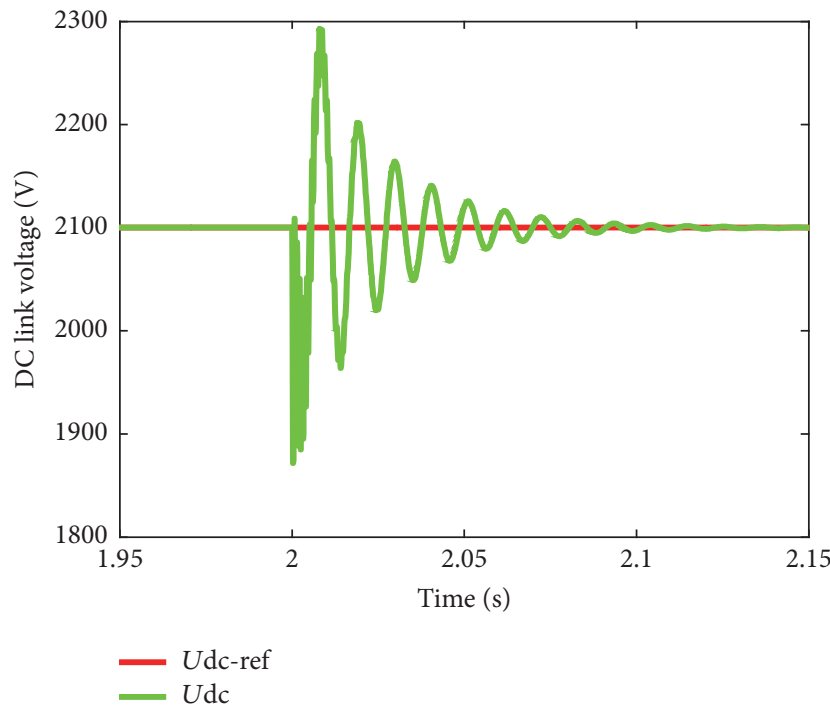

(b) VOC strategy

Figure 14: dc-link voltage (V) (with nominal values).

will not be transmitted to the dc-link system voltage and the converter dc-link voltage is controlled invariable at the reference value $2100 \mathrm{~V}$ as in Figure 19.

\section{Conclusion}

This paper has presented a nonlinear backstepping approach of WFS driven DDSG operating under normal and voltage drop situations. A proposed control has been investigated to deal with problems of simultaneous control of the DDSG speeds and the dc-link voltage to achieve Maximum Power
Tracking and pitch control. Simulation research on a 6-MWDDSG Wind Farm System validates the proposed control strategy. Performance comparison and evaluation with Vector Oriented Control (VOC) are provided under a wide range of functioning conditions, three-phase voltage dips, and the probable occurrence of uncertainties. The main conclusions are summarized as follows: (1) The proposed backstepping strategy can guarantee acceptable global regulation and tracking performance. (2) The proposed control strategy offers remarkable characteristics such as excellent dynamic and steady state performance under varying wind speed and 


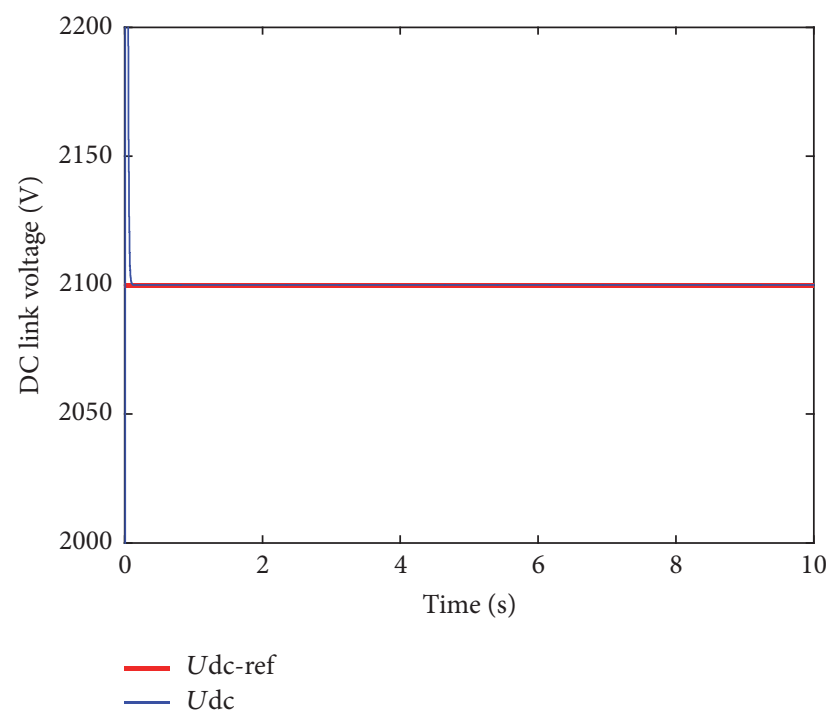

(a) Backstepping control

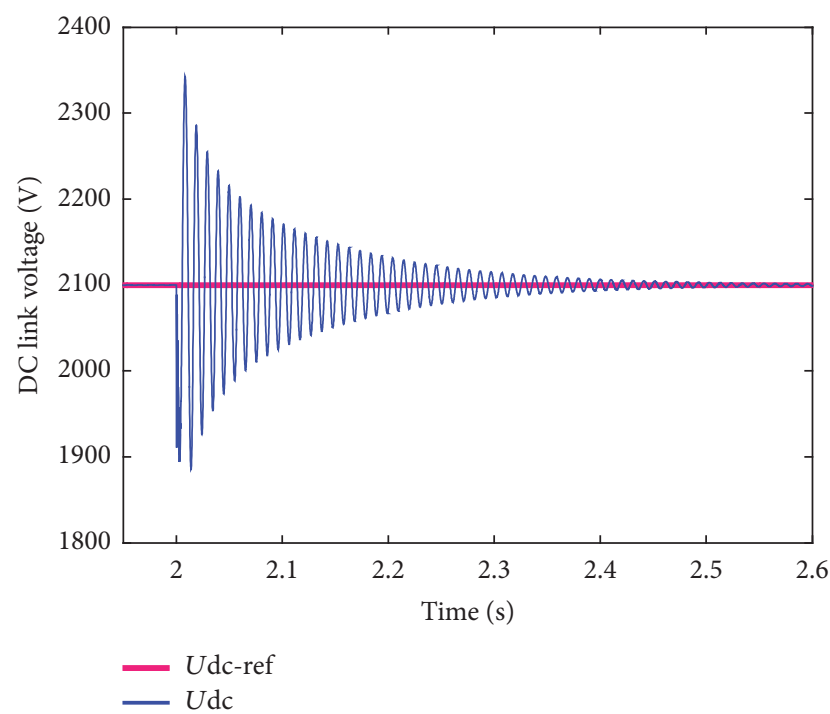

(b) VOC strategy

FIGURE 15: dc-link voltage (V) (with parameter variations).

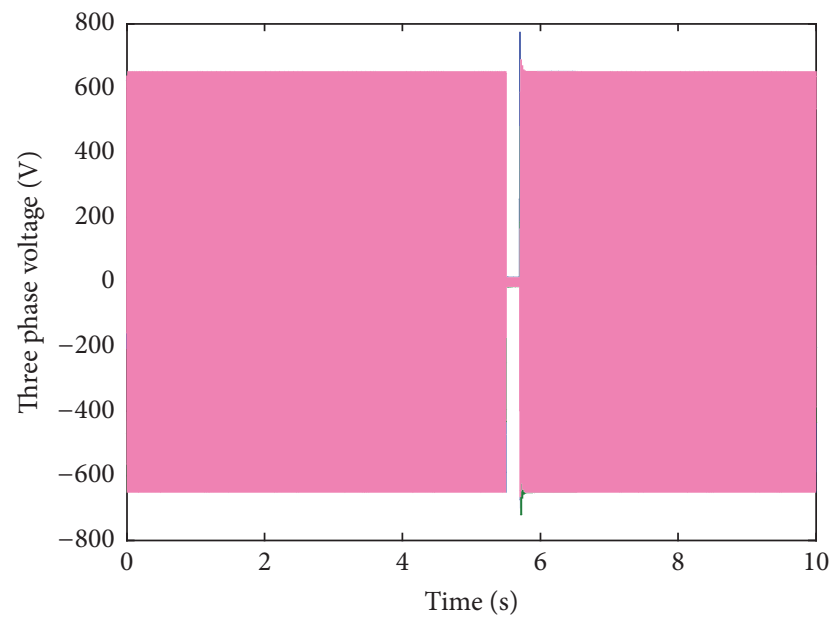

(a) Backstepping control

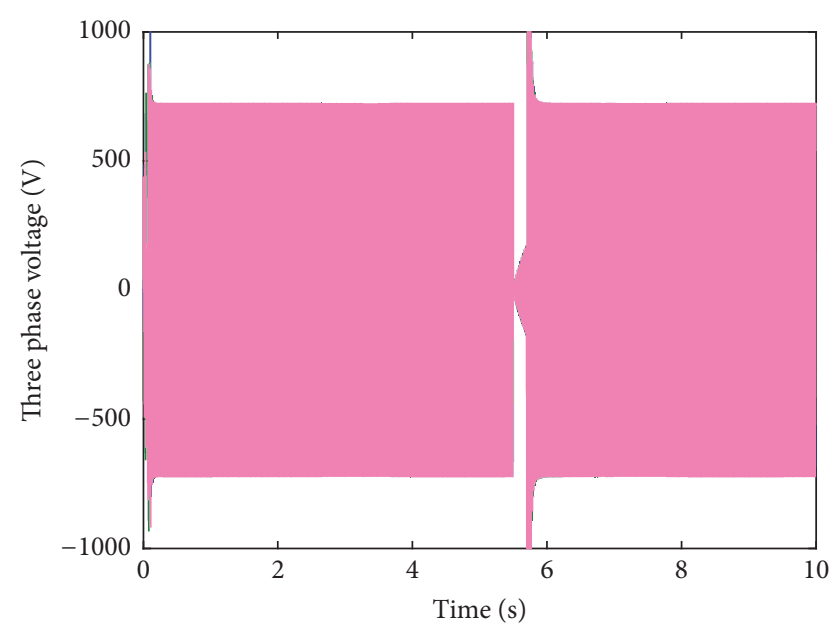

(b) VOC strategy

FIGURE 16: Waveforms of three-phase voltage at Bus 4.

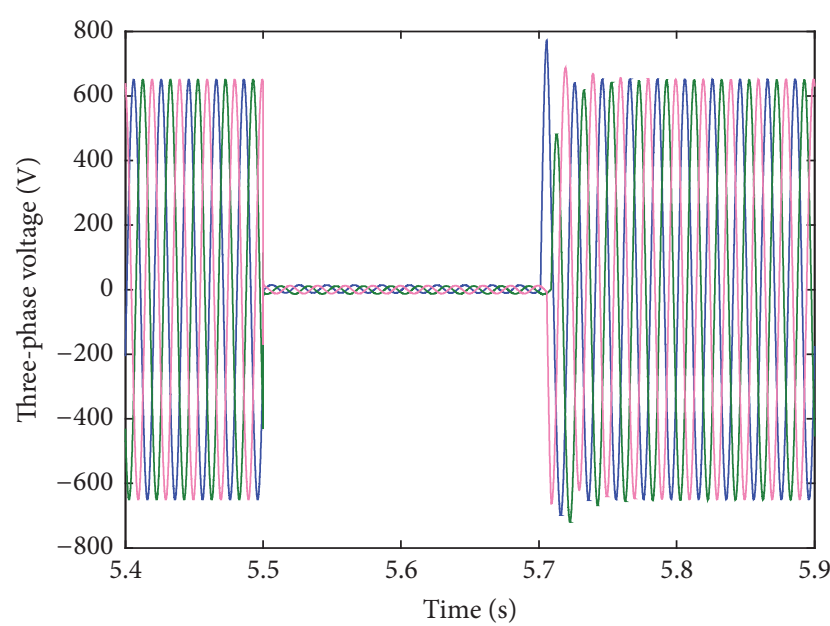

(a) Backstepping control

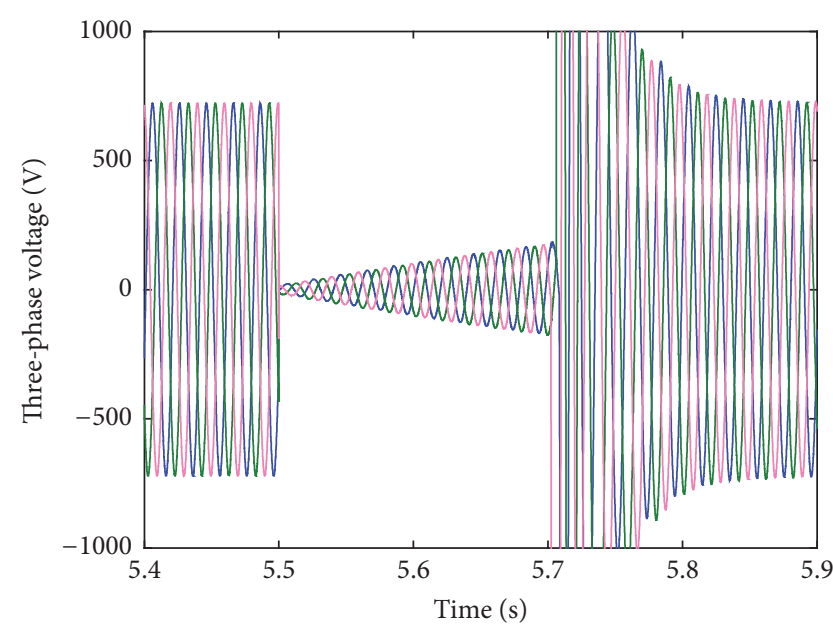

(b) VOC strategy

FIGURE 17: Zoom-in view of three-phase voltage at Bus 4. 


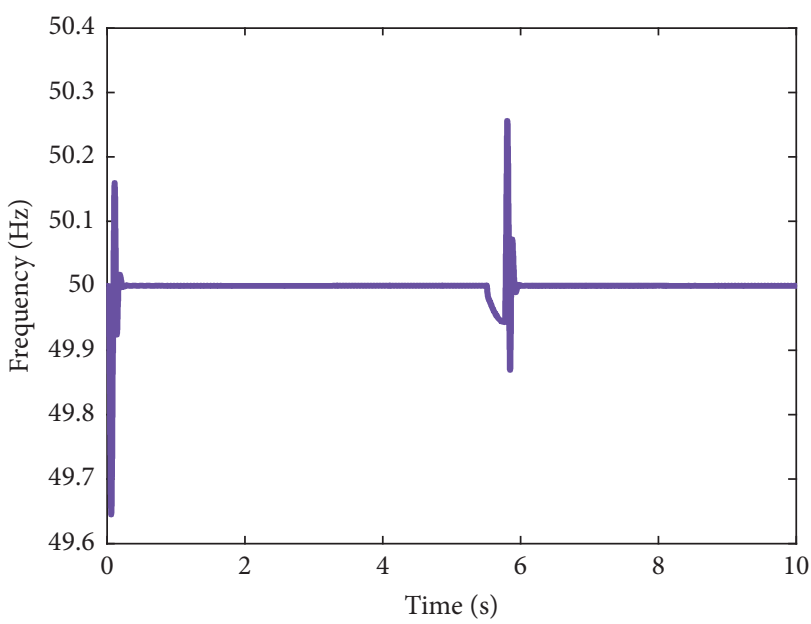

(a) Backstepping control

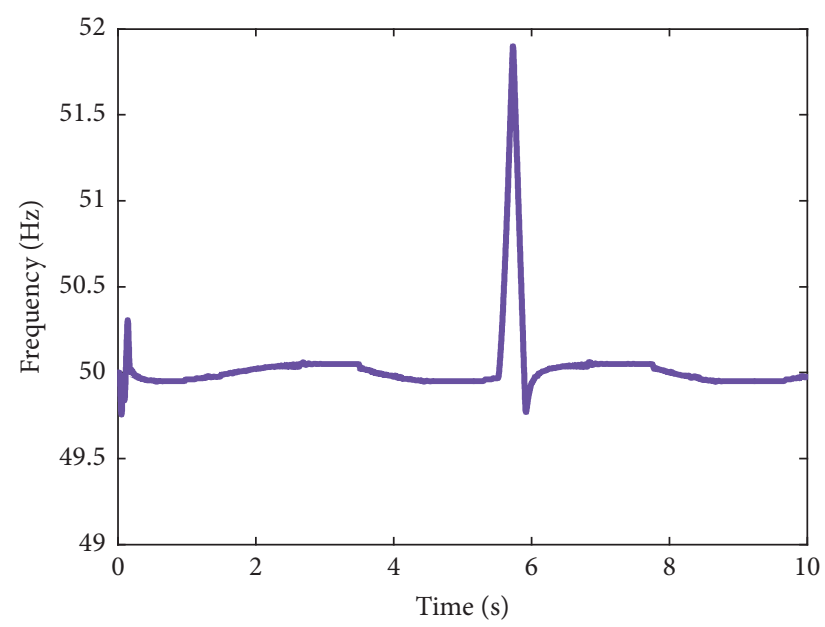

(b) VOC strategy

FIGURE 18: Frequency response of the VS-WFS under grid faults.

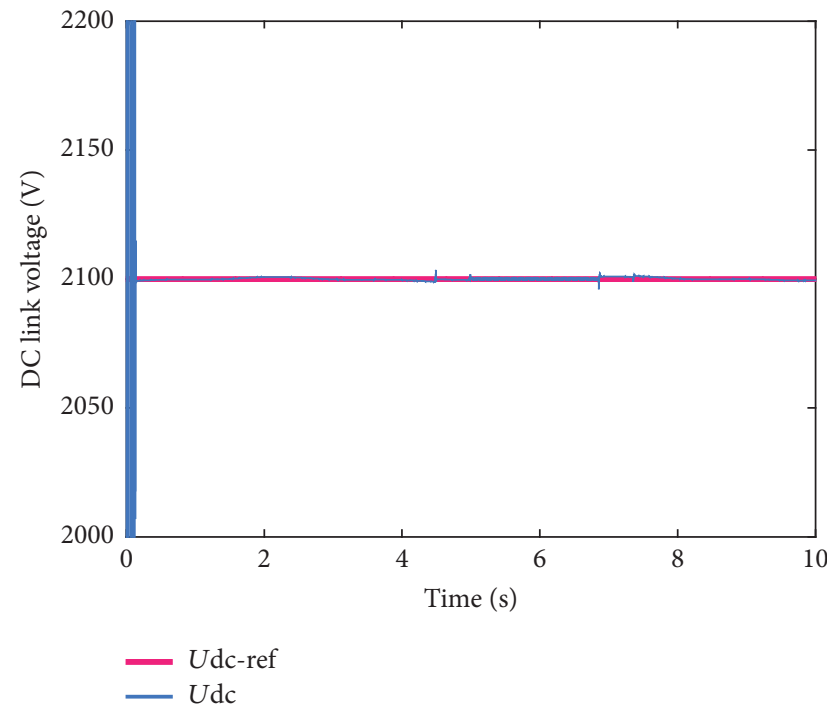

(a) Backstepping control

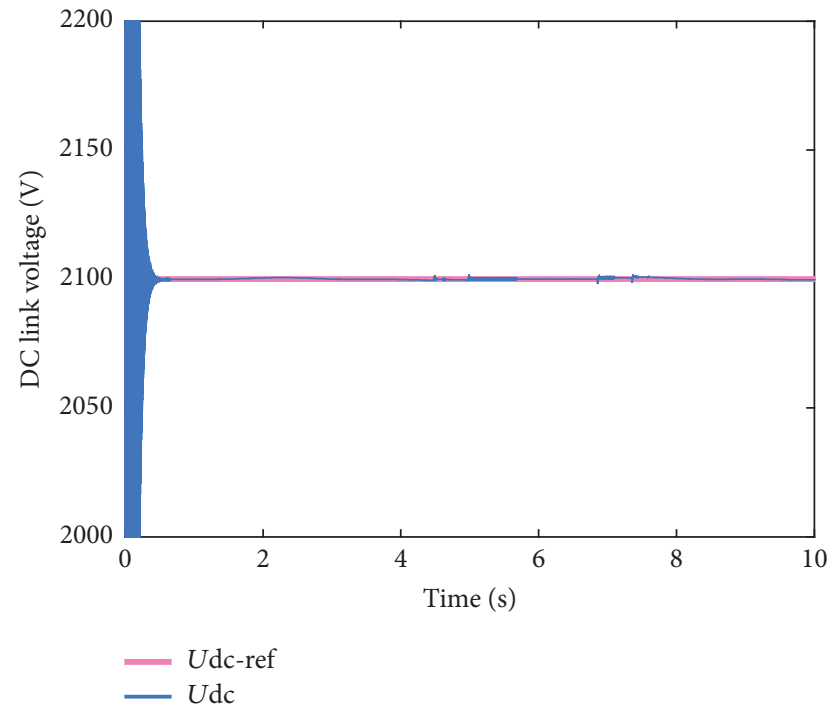

(b) VOC strategy

FIGURE 19: dc-link voltage (V).

robustness to parametric variations in the WFS and under severe faults of grid voltage.

\section{Conflicts of Interest}

The authors declare that they have no conflicts of interest regarding the publication of this paper.

\section{References}

[1] A. Parastar and J.-K. Seok, "High-gain resonant switched-capacitor cell-based DC/DC converter for offshore wind energy systems," IEEE Transactions on Power Electronics, vol. 30, no. 2 , pp. 644-656, 2015.

[2] P. Yu, W. Zhou, H. Sun, J. Bai, J. Liu, and Y. Liu, "A new pattern wind power suppression system based on hybrid energy storage techniques," Energy Studies Review, vol. 4, no. 1, pp. 1-24, 2013.
[3] Y. Errami, M. Ouassaid, and M. Maarouf, "A performance comparison of a nonlinear and a linear control for grid connected PMSG wind energy conversion system," International Journal of Electrical Power \& Energy Systems, vol. 68, pp. 180-194, 2015.

[4] F. Luo, K. Meng, Z. Y. Dong, Y. Zheng, Y. Chen, and K. P. Wong, "Coordinated operational planning for wind farm with battery energy storage system," IEEE Transactions on Sustainable Energy, vol. 6, no. 1, pp. 253-262, 2015.

[5] A. M. Kassem, "Modeling and control design of a stand alone wind energy conversion system based on functional model predictive control," Energy Studies Review, vol. 3, no. 3, pp. 303-323, 2012.

[6] Y. Errami, M. Ouassaid, M. Cherkaoui, and M. Maaroufi, "Variable structure sliding mode control and direct torque control of wind power generation system based on the pm synchronous generator," Journal of Electrical Engineering, vol. 66, no. 3, pp. 121-131, 2015. 
[7] X. She, A. Q. Huang, F. Wang, and R. Burgos, "Wind energy system with integrated functions of active power transfer, reactive power compensation, and voltage conversion," IEEE Transactions on Industrial Electronics, vol. 60, no. 10, pp. 4512-4524, 2013.

[8] M. Benchagra, M. Hilal, Y. Errami, M. Ouassaid, and M. Maaroufi, "Modeling and control of SCIG based variable-speed with power factor control," International Review on Modelling and Simulations, vol. 4, no. 3, pp. 1007-1014, 2011.

[9] L. Peng, H. Ma, Y. Li, F. Bruno, and L. Xu, "Reconfiguration of control strategies for high power DFIG wind turbine system with grid fault ride-through capability," in Proceedings of the 2013 15th European Conference on Power Electronics and Applications, EPE 2013, fra, September 2013.

[10] K. Nishida, T. Ahmed, S. Mekhilef, and M. Nakaoka, "Costeffective high-reliability power-conditioning system used for grid integration of variable-speed wind turbine," in Proceedings of the 1st International Future Energy Electronics Conference, IFEEC 2013, pp. 530-535, twn, November 2013.

[11] M. Hilal, Y. Errami, M. Benchagra, M. Maaroufi, M. Cherkaoui, and M. Ouassaid, "Doubly fed induction generator wind farm fault ride-through capability," in Proceedings of the 2012 International Conference on Multimedia Computing and Systems, ICMCS 2012, pp. 1079-1082, May 2012.

[12] J. Chen, J. Chen, and C. Gong, "On optimizing the aerodynamic load acting on the turbine shaft of pmsg-based direct-drive wind energy conversion system," IEEE Transactions on Industrial Electronics, vol. 61, no. 8, pp. 4022-4031, 2014.

[13] O. Alizadeh and A. Yazdani, "A strategy for real power control in a direct-drive PMSG-based wind energy conversion system," IEEE Transactions on Power Delivery, vol. 28, no. 3, pp. 12971305, 2013.

[14] Y. Errami, M. Ouassaid, and M. Maaroufi, "Optimal Power Control Strategy of Maximizing Wind Energy Tracking and Different Operating Conditions for Permanent Magnet Synchronous Generator Wind Farm," in Proceedings of the International Conference on Technologies and Materials for Renewable Energy, Environment and Sustainability, TMREES 2015, pp. 477-490, lbn, April 2015.

[15] S. Alshibani, V. G. Agelidis, and R. Dutta, "Lifetime cost assessment of permanent magnet synchronous generators for mw level wind turbines," IEEE Transactions on Sustainable Energy, vol. 5, no. 1, pp. 10-17, 2014.

[16] X.-C. Li, Y.-N. Zhao, and X. Zui-Bing, "Nonlinear control of permanent magnet wind turbine generation (PSMG)," in Proceedings of the 2013 International Conference on Power, Energy and Control, ICPEC 2013, pp. 658-661, ind, February 2013.

[17] S. Yang and L. Zhang, "Modeling and control of the PMSG wind generation system with a novel controller," in Proceedings of the 2013 3rd International Conference on Intelligent System Design and Engineering Applications, ISDEA 2013, pp. 946-949, chn, January 2013.

[18] S. Zhou, J. Liu, L. Zhou, and Y. Zhu, "Improved DC-link voltage control of PMSG WECS based on feedback linearization under grid faults," in Proceedings of the 28th Annual IEEE Applied Power Electronics Conference and Exposition, APEC 2013, pp. 2895-2899, March 2013.

[19] Z. Zhang, Y. Zhao, W. Qiao, and L. Qu, "A space-vector-modulated sensorless direct-torque control for direct-drive PMSG wind turbines," IEEE Transactions on Industry Applications, vol. 50, no. 4, pp. 2331-2341, 2014.
[20] C. Huang, F. Li, T. Ding, Z. Jin, and X. Ma, "Second-order cone programming-based optimal control strategy for wind energy conversion systems over complete operating regions," IEEE Transactions on Sustainable Energy, vol. 6, no. 1, pp. 263271, 2015.

[21] G. Buticchi, E. Lorenzani, F. Immovilli, and C. Bianchini, "Active rectifier with integrated system control for microwind power systems," IEEE Transactions on Sustainable Energy, vol. 6, no. 1, pp. 60-69, 2015.

[22] F. Bu, Y. Hu, W. Huang, S. Zhuang, and K. Shi, "Wide-speedrange-operation dual stator-winding induction generator DC generating system for wind power applications," IEEE Transactions on Power Electronics, vol. 30, no. 2, pp. 561-573, 2015.

[23] F. Blaabjerg and K. Ma, "Future on power electronics for wind turbine systems," IEEE Journal of Emerging and Selected Topics in Power Electronics, vol. 1, no. 3, pp. 139-152, 2013.

[24] K. Ma, M. Liserre, and F. Blaabjerg, "Comparison of multi-MW converters considering the determining factors in wind power application," in Proceedings of the 5th Annual IEEE Energy Conversion Congress and Exhibition, ECCE 2013, pp. 4754-4761, September 2013.

[25] I. Jlassi, J. O. Estima, S. Khojet El Khil, N. Mrabet Bellaaj, and A. J. Marques Cardoso, "Multiple open-circuit faults diagnosis in back-to-back converters of PMSG drives for wind turbine systems," IEEE Transactions on Power Electronics, vol. 30, no. 5, pp. 2689-2702, 2015.

[26] E. Giraldo and A. Garces, "An adaptive control strategy for a wind energy conversion system based on PWM-CSC and PMSG," IEEE Transactions on Power Systems, vol. 29, no. 3, pp. 1446-1453, 2014.

[27] Y. Errami, M. Ouassaid, and M. Maaroufi, "Modelling and optimal power control for permanent magnet synchronous generator wind turbine system connected to utility grid with fault conditions," World Journal of Modelling and Simulation, vol. 11, no. 2, pp. 123-135, 2015.

[28] T. H. Nguyen and D.-C. Lee, "Advanced fault ride-through technique for PMSG wind turbine systems using line-side converter as STATCOM," IEEE Transactions on Industrial Electronics, vol. 60, no. 7, pp. 2842-2850, 2013.

[29] N. M. A. Freire and A. J. M. Cardoso, "A fault-tolerant direct controlled pmsg drive for wind energy conversion systems," IEEE Transactions on Industrial Electronics, vol. 61, no. 2, pp. 821-834, 2014.

[30] R. Li and D. Xu, "Parallel operation of full power converters in permanent-magnet direct-drive wind power generation system," IEEE Transactions on Industrial Electronics, vol. 60, no. 4, pp. 1619-1629, 2013.

[31] C. Xia, Z. Wang, T. Shi, and Z. Song, "A novel cascaded boost chopper for the wind energy conversion system based on the permanent magnet synchronous generator," IEEE Transactions on Energy Conversion, vol. 28, no. 3, pp. 512-522, 2013.

[32] K.-H. Kim, T. L. Van, D.-C. Lee, S.-H. Song, and E.-H. Kim, "Maximum output power tracking control in variable-speed wind turbine systems considering rotor inertial power," IEEE Transactions on Industrial Electronics, vol. 60, no. 8, pp. 32073217, 2013.

[33] Y. Errami, M. Ouassaid, and M. Maaroufi, "Control of grid connected PMSG based variable speed wind energy conversion system," International Review on Modelling and Simulations, vol. 5, no. 2, pp. 655-664, 2012.

[34] H. Polinder, D. Bang, R. P. J. O. M. van Rooij, A. S. McDonald, and M. A. Mueller, "10 MW Wind Turbine Direct-Drive 
Generator Design with Pitch or Active Speed Stall Control," in Proceedings of the IEEE International Conference On Electric Machines \& Drives (IEMDC’07), vol. 2, pp. 1390-1395, 2007.

[35] C. J. Spruce and J. K. Turner, "Tower vibration control of active stall wind turbines," IEEE Transactions on Control Systems Technology, vol. 21, no. 4, pp. 1049-1066, 2013.

[36] K.-H. Kim, Y.-C. Jeung, D.-C. Lee, and H.-G. Kim, "LVRT scheme of PMSG wind power systems based on feedback linearization," IEEE Transactions on Power Electronics, vol. 27, no. 5, pp. 2376-2384, 2012.

[37] S. Li, T. A. Haskew, R. P. Swatloski, and W. Gathings, "Optimal and direct-current vector control of direct-driven PMSG wind turbines," IEEE Transactions on Power Electronics, vol. 27, no. 5, pp. 2335-2337, 2012.

[38] Y. Errami, M. Maaroufi, and M. Ouassaid, "A MPPT vector control of electric network connected Wind Energy Conversion System employing PM Synchronous Generator," in Proceedings of the 1st International Renewable and Sustainable Energy Conference, IRSEC 2013, pp. 228-233, March 2013.

[39] S. Dong, H. Li, and Y. Wang, "Low voltage ride through capability enhancement of PMSG-based wind turbine," in Proceedings of the International Conference on Sustainable Power Generation and Supply (SUPERGEN 2012), pp. 66-66, Hangzhou, China.

[40] S. Alepuz, A. Calle, S. Busquets-Monge, S. Kouro, and B. Wu, "Use of stored energy in PMSG rotor inertia for low-voltage ride-through in back-to-back NPC converter-based wind power systems," IEEE Transactions on Industrial Electronics, vol. 60, no. 5, pp. 1787-1796, 2013.

[41] Y. Errami, M. Maaroufi, M. Cherkaoui, and M. Ouassaid, "Maximum power point tracking strategy and direct torque control of permanent magnet synchronous generator wind farm," in Proceedings of the 2012 International Conference on Complex Systems (ICCS), pp. 1-6, Agadir, Morocco, November 2012.

[42] M. Krstic, I. Kanellakopoulos, and P. V. Kokotovic, Nonlinear and Adaptive, Control Design Book, John Wiley \& Sons, New York, NY, USA, 1995.

[43] G. Foo and M. F. Rahman, "Direct torque and flux control of an IPM synchronous motor drive using a backstepping approach," IET Electric Power Applications, vol. 3, no. 5, pp. 413-421, 2009.

[44] N. Khan, S. F. Rabbi, M. J. Hinchey, and M. A. Rahman, "Adaptive backstepping based maximum power point tracking control for a variable speed marine current energy conversion system," in Proceedings of the 2013 26th IEEE Canadian Conference on Electrical and Computer Engineering, CCECE 2013, can, May 2013.

[45] C.-S. Ting, Y.-N. Chang, B.-W. Shi, and J.-F. Lieu, "Adaptive backstepping control for permanent magnet linear synchronous motor servo drive," IET Electric Power Applications, vol. 9, no. 3, pp. 265-279, 2015.

[46] R.-J. Wai, C.-Y. Lin, W.-C. Wu, and H.-N. Huang, "Design of backstepping control for high-performance inverter with standalone and grid-connected power-supply modes," IET Power Electronics, vol. 6, no. 4, pp. 752-762, 2013.

[47] S.-Y. Ruan, G.-J. Li, X.-H. Jiao, Y.-Z. Sun, and T. T. Lie, "Adaptive control design for VSC-HVDC systems based on backstepping method," Electric Power Systems Research, vol. 77, no. 5-6, pp. 559-565, 2007.

[48] A. Karthikeyan, S. K. Kummara, C. Nagamani, and G. S. Ilango, "Power control of grid connected doubly fed induction generator using Adaptive BackStepping approach," in Proceedings of the 2011 10th International Conference on Environment and Electrical Engineering, EEEIC.EU 2011, ita, May 2011.
[49] Y. Errami, M. Ouassaid, and M. Maaroufi, "Modeling and variable structure power control of PMSG based variable speed wind energy conversion system," Journal of Optoelectronic and Advanced Materials, vol. 15, no. 11-12, pp. 1248-1255, 2013.

[50] C. Pradhan and C. N. Bhende, "Adaptive deloading of standalone wind farm for primary frequency control," Energy Studies Review, vol. 6, no. 1, pp. 109-127, 2014.

[51] Y. Errami, M. Hilal, M. Benchagra, M. Ouassaid, and M. Maarouf, "Nonlinear control of MPPT and grid connected for variable speed wind energy conversion system based on the PMSG," Journal of Theoretical and Applied Information Technology, vol. 39, no. 2, pp. 204-217, 2012.

[52] Y. Errami, M. Benchagra, M. Hillal, M. Ouassaid, and M. Maaroufi, "MPPT strategy and direct torque control of PMSG used for variable Speed Wind Energy Conversion System," International Review on Modelling and Simulations, vol. 5, no. 2, pp. 887-898, 2012.

[53] J. E. Slotine and W. Li, Applied Nonlinear Control, Prentice Hall, Englewood Cliffs, New Jersey, NJ, USA, 1991.

[54] Y. Errami, M. Hilal, M. Benchagra, M. Maaroufi, and M. Ouassaid, "Nonlinear control of MPPT and grid connected for wind power generation systems based on the PMSG," in Proceedings of the 2012 International Conference on Multimedia Computing and Systems, ICMCS 2012, pp. 1055-1060, May 2012.

[55] M. Benchagra, M. Hilal, Y. Errami, M. Maaroufi, and M. Ouassaid, "Nonlinear control of DC-bus voltage and power for voltage source inverter," in Proceedings of the 2012 International Conference on Multimedia Computing and Systems, ICMCS 2012, pp. 1049-1054, May 2012.

[56] Y. Errami, M. Ouassaid, and M. Maaroufi, "Control of a PMSG based wind energy generation system for power maximization and grid fault conditions," in Proceedings of the International Conference on Mediterranean Green Energy Forum, MGEF 2013, pp. 220-229, June 2013. 


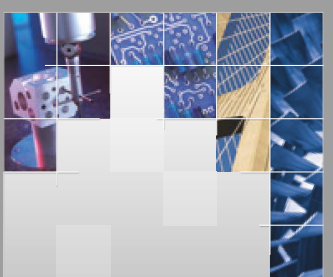

\section{Enfincering}
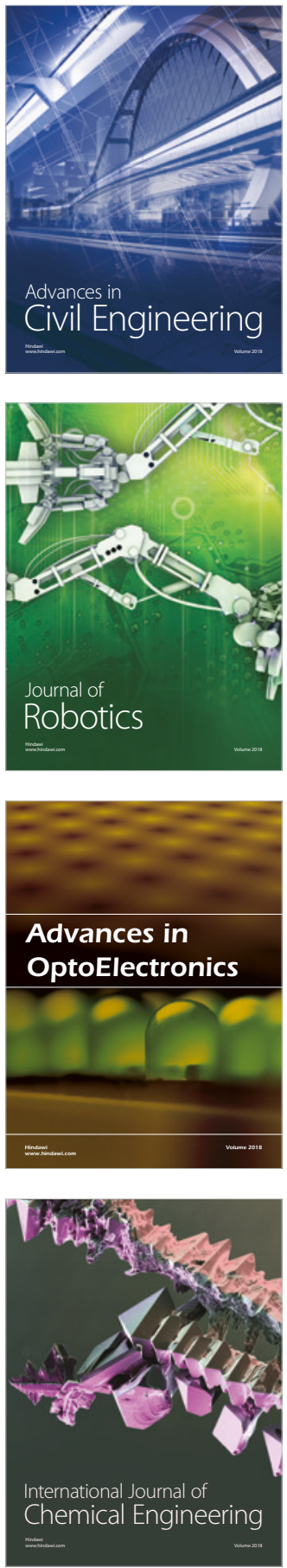

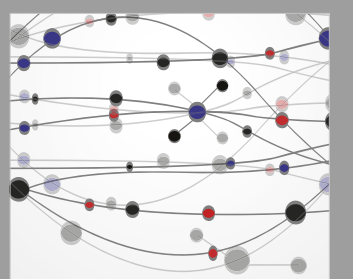

\section{Rotating \\ Machinery}

The Scientific World Journal

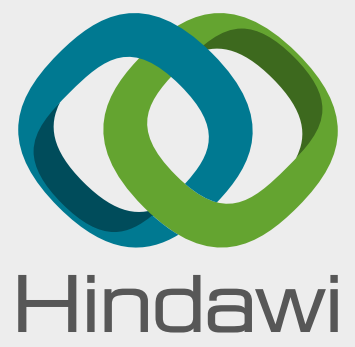

Submit your manuscripts at

www.hindawi.com
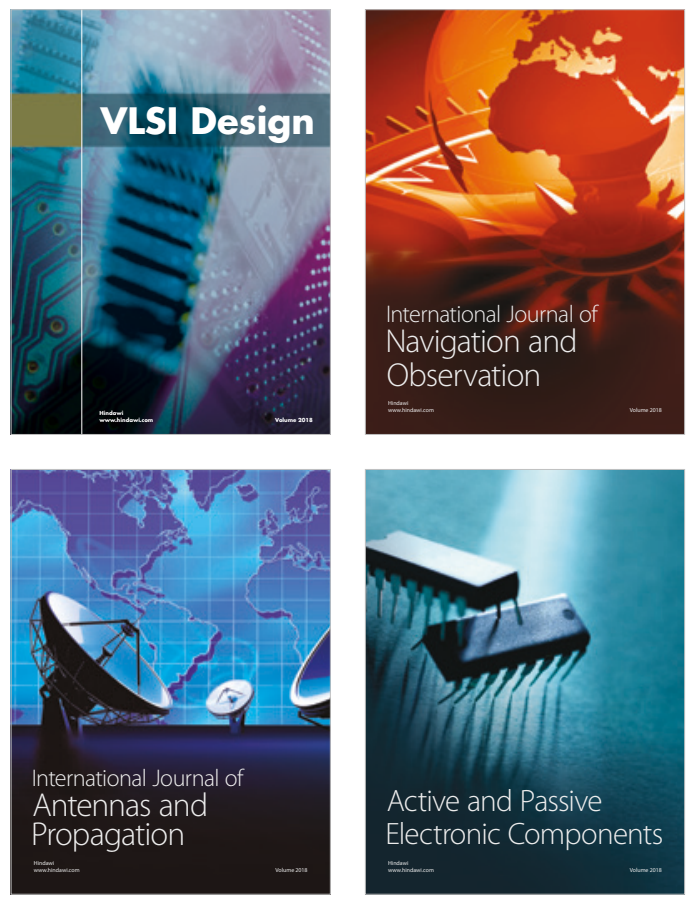
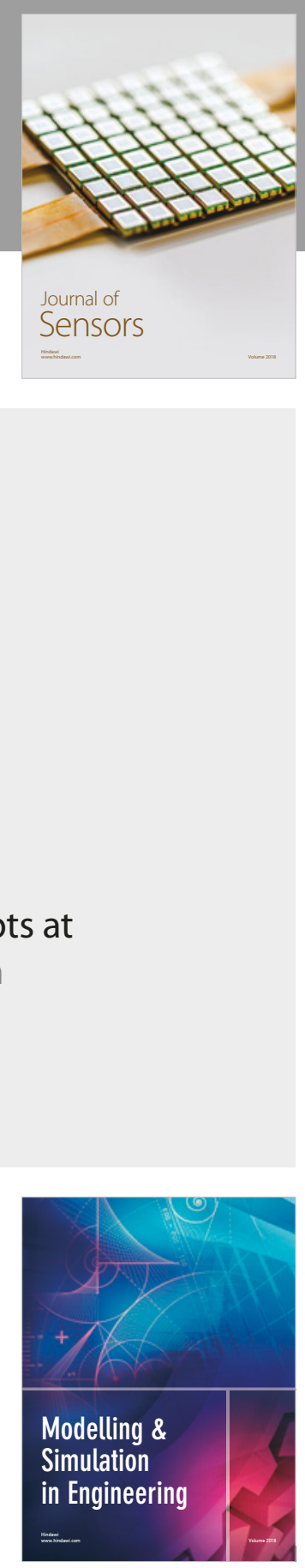

\section{Advances \\ Multimedia}
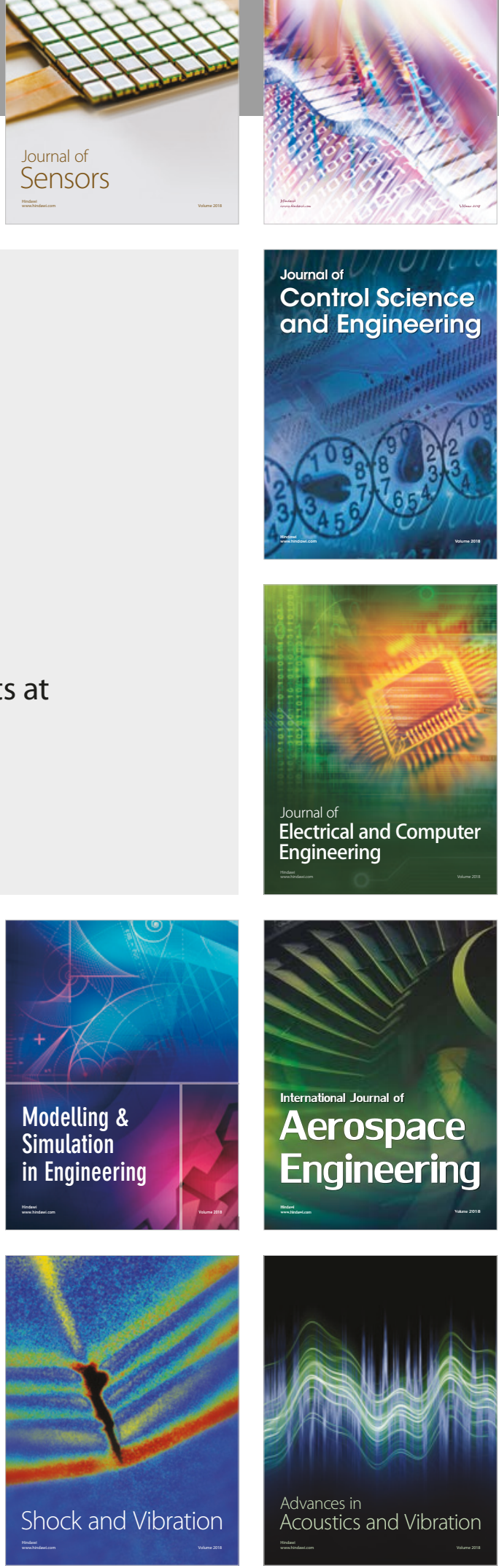